\title{
Article \\ Distinctly Different Morphologies of Bimetallic Au-Ag Nanostructures and Their Application in Submicromolar SERS-Detection of Free Base Porphyrin
}

\author{
Iveta Vilímová (D) and Karolína Šišková *(D) \\ Department of Experimental Physics, Faculty of Science, Palacký University in Olomouc, \\ Tr̆. 17. Listopadu 1192/12, 77146 Olomouc, Czech Republic; vilimovai4@gmail.com \\ * Correspondence: karolina.siskova@upol.cz
}

Citation: Vilímová, I.; Šišková, K. Distinctly Different Morphologies of Bimetallic Au-Ag Nanostructures and Their Application in Submicromolar SERS-Detection of Free Base Porphyrin. Nanomaterials 2021, 11, 2185. https://doi.org/10.3390/ nano11092185

Academic Editor: Onofrio M. Maragò

Received: 13 August 2021

Accepted: 21 August 2021

Published: 26 August 2021

Publisher's Note: MDPI stays neutral with regard to jurisdictional claims in published maps and institutional affiliations.

Copyright: (c) 2021 by the authors. Licensee MDPI, Basel, Switzerland. This article is an open access article distributed under the terms and conditions of the Creative Commons Attribution (CC BY) license (https:// creativecommons.org/licenses/by/ $4.0 /)$.

\begin{abstract}
Core-shell Au-Ag nanostructures (Au-AgNSs) are prepared by a seed-meditated growth, i.e., by a two-step process. The synthetic parameters greatly influence the morphologies of the final bimetallic Au-AgNSs, their stability and application potential as surface-enhanced Raman scattering (SERS) substrates. Direct comparison of several types of Au NPs possessing different surface species and serving as seeds in Au-AgNSs synthesis is the main objective of this paper. Borohydride-reduced (with varying stages of borohydride hydrolysis) and citrate-reduced Au NPs were prepared and used as seeds in Au-AgNSs generation. The order of reactants in seed-mediated growth procedure represents another key factor influencing the final Au-AgNSs characteristics. Electronic absorption spectra, dynamic light scattering, zeta potential measurements, energy dispersive spectroscopy and transmission electron microscopy were employed for Au-AgNSs characterization. Subsequently, possibilities and limitations of SERS-detection of unperturbed cationic porphyrin, 5,10,15,20-tetrakis(1-methyl-4-pyridyl)21H,23H-porphine (TMPyP), were investigated by using these Au-AgNSs. Only the free base (unperturbed) SERS spectral form of TMPyP is detected in all types of $\mathrm{Au}$-AgNSs. It reports about a well-developed envelope of organic molecules around each Au-AgNSs which prevents metalation from occuring. TMPyP, attached via ionic interaction, was successfully detected in $10 \mathrm{nM}$ concentration due to Au-AgNSs.
\end{abstract}

Keywords: bimetallic nanoparticles; silver-gold particles; seeded-growth; reactant order; nanoparticle morphology; TMPyP; free base porphyrin; non-metalated porphyrin; SERS

\section{Introduction}

Among metal nanostructures (NSs), gold and silver NSs are the most commonly used candidates in optical, catalytic, biomedical applications [1,2] due to their unique physico-chemical properties. The most intriguing property of Au and Ag NSs is their localized surface plasmon resonance (LSPR) [3-7] which is for these noble metal NSs conveniently located in the visible (vis) and near infrared (NIR) regions. The LSPR occurs due to d-d band transitions and makes Au and Ag NSs particularly suitable for biomedical applications [7]. Exposing Au or Ag NSs to light leads to many LSPR-related processes, including Mie extinction (absorption and scattering), surface-enhanced Raman scattering (SERS) and photothermal effect [1].

The combination of Au and Ag NSs in core-shell arrangements is preferentially used and investigated because different shapes and morphologies of the final NSs can be created, not only spherical, but also triangular, cubic, dumbbells, bipyramids, pentagonal rods, wires, hexagonal platelike, octahedral, and multiple-twinned decahedral structures in refs [1,2,7-12]. The combination of these two noble metals prepared as core-shell structures revealed improved properties, namely in LSPR-based and SERS-based spectroscopic detection of different species (e.g., As(III) [13], $\mathrm{Cr}(\mathrm{VI})$ [14] etc.), in comparison to pure Ag and/or Au nanostructures (e.g., [15,16]). 
Owing to the similarity of $\mathrm{Au}$ and Ag lattice constants $(0.408$ and $0.409 \mathrm{~nm}$, respectively) [17], these two noble metals can be easily combined within one nanostructure. It should be noted that the co-reduction of $\mathrm{HAuCl}_{4}$ and $\mathrm{AgNO}_{3}$ usually results in nanoalloys (e.g., [18-20]), although under specific conditions (usage of pomegranate fruit juice as reducing agent and $\mathrm{Au}(\mathrm{III}): \mathrm{Ag}(\mathrm{I})$ molar ratio of 1:1) [9] Au-Ag core-shell NPs were generated as well.

Generally, the reproducible preparation of Au-Ag core-shell NSs requires a two-step process; seed-mediated growth and weak reducing agents, such as for instance L-ascorbic acid, are used. Ascorbic acid (Asc), also known as Vitamin C, is considered a relatively weak reductant under non-alkaline conditions [21]. This could benefit the synthesis of metal NSs via seed-mediated growth because the self-nucleation of newly formed metal atoms is suppressed [22]. Asc forms three different species depending on the solution $\mathrm{pH}$ : ascorbic acid, ascorbate, and diascorbate. For all three forms, the mechanism involved in the syntheses of noble-metal NSs are similar to each other in terms of electron transfer and the oxidized product formed in the redox reaction (dehydroascorbate) [21]. Interestingly, the seed-mediated growth process of $\mathrm{Au}$ (core)-Ag(shell)NSs was employed for the quantitative LSPR-based detection of vitamin C concentration [23].

Ding et $\mathrm{Zhu}$ [24] stated that a different amount of Au seeds (generated from $\mathrm{HAuCl}_{4}$, $\mathrm{CTAB}, \mathrm{NaBH}_{4}$ ) resulted in different size of Au nanocubes (prepared in the growth solution containing Asc, CTAB, $\mathrm{HAuCl}_{4}$ ) which served as seeds in the next step of Au-Ag nanocubes preparation (i.e., addition of $\mathrm{CTAB}, \mathrm{AgNO}_{3}, \mathrm{Asc}, \mathrm{NaOH}$ ). The thickness of silver shell was fine-tuned by changing the volume of gold nanocubes and silver nitrate [24].

Similarly, Pei and coworkers [25] reported that by varying the concentration of $\mathrm{AgNO}_{3}$ and amount of $\mathrm{Au}$ seeds (synthesized by using sodium citrate and $\mathrm{HAuCl}_{4}$ ), the size of $\mathrm{Au}-\mathrm{Ag}$ nanospheres (arising from the seed mediated growth by adding $\mathrm{Asc}$ and $\mathrm{AgNO}_{3}$ ) can be controlled.

From the above mentioned examples, it is obvious that detailed experimental conditions are crucial in the generation of Au-Ag core-shell NSs of different morphologies and varying shell-thicknesses. Until now, several parameters have been thoroughly investigated: various types of additional capping agents on seeds and changes in their concentrations, varying concentrations of $\mathrm{Au}$ seeds and $\mathrm{AgNO}_{3}$, changes in reaction times and stirring rates $[11,12,15,20,23-33]$.

Concerning the order of reactants in seed-mediated growth using Asc, very limited attention has been paid to this factor in the literature so far $[27,28,30]$. Zheng and coworkers [30] demonstrated that the order of reactants played a key role in the formation of Au-AgNSs and their LSPR occurrence. However, their [30] reaction mixture contained CTAB (besides $\mathrm{HAuCl}_{4}$ ) which formed micelles upon addition of Asc.

Due to the mean size of the as-prepared Au-Ag core-shell NSs (tens of nanometers), they can be exploited in the detection of low concentrations of a model molecule by SERS [34]. Frequently, rhodamine 6G (R6G) (e.g., [11,24,26,29,35]) and/or crystal violet (CV) (e.g., [8]) were used by many authors as model molecules evaluating SERS-efficiency of the generated Au-AgNSs. However, we are systematically using porphyrins as SERSreporter biomolecules because they can better evaluate the surface features of NSs, such as metalation predispositions (i.e., the predispositions for incorporation of a metal ion into a porphyrin core), oxidation state of Ag ions at the surface of NSs, etc. [36-41]. Based on previous studies, tetracationic TMPyP (5,10,15,20-tetrakis(1-methyl-4-pyridyl)21H,23Hporphine) can interact with $\mathrm{Ag}(\mathrm{I})$ and/or $\mathrm{Ag}(0)$ surfaces, revealing metalation markers in slightly different positions leading thus to different SERS-spectral patterns [40-43]. The metalation of a free base porphyrin molecule represents an undesirable effect from the viewpoint of the unperturbed free base porphyrin SERS detection in bioanalytical applications $[44,45]$. There were several attempts to prevent the metalation (i) by employing spacers between TMPyP and Ag surface [37] and/or (ii) by changing the envelope around Ag NPs via different synthetic procedure [38]. The role of citrates on the surface of AgNPs 
serving as a pre-orienting matrix for porphyrin molecules (not only TMPyP, but also other types of porphyrins) was found out by us in [39].

In this paper, we are dealing with the creation of $\mathrm{Au}$ (core)—Ag (shell) NSs bearing resemblance to flowers of different morphologies, which is achieved simply by changing the Au seed type. In general, flower-like nanoparticles possess nanometer-sized intersticies on the surface which results in SERS enhancement. In our case, the Au-Ag core-shell arrangement is the most convenient one for several reasons: (i) AgNSs represent better SERS enhancers than AuNSs [15,26]; (ii) reproducibility and monodispersity of AuNSs, serving as seeds (in the next step of the synthesis), are much better than that of Ag. This is due to the fact that gold NSs can be easily made, measured, and modelled which is stated as the 3M's principle in the literature [5]. (iii) Galvanic replacement (which takes place in the reverse structure, i.e., Ag-Au core-shell—e.g., [46]) is avoided.

In the present study, two different, but well-known types of AuNPs were synthesized and they served as seeds in the next step of the final Au-AgNSs preparation: borohydrideand citrate-reduced AuNPs, labelled as AuBhr and AuCitr, respectively. These two were intentionally chosen for their general frequent usage, but nobody has compared them directly yet when serving as seeds in Au-AgNSs generation. A few facts about each reducing agent, of which residues are present at Au seed surface, should be reminded here.

Sodium borohydride is a strong reductant, often used in metal nanoclusters and NPs formation because it reduces a salt precursor within a very short time. The fast formation of plenty tiny metal nanocrystals leads to growth via attachment [47] and thus, it limits the utility of $\mathrm{NaBH}_{4}$ in the shape-controlled synthesis [21]. Mechanistically, the important step during the redox process using $\mathrm{NaBH}_{4}$ is its hydrolysis to $\mathrm{B}(\mathrm{OH})_{4}{ }^{-}$and consequently, surface chemistry on noble-metal nanostructures in the early stages of their formation $[48,49]$. Of course, the redox potential of $\mathrm{NaBH}_{4}$ strongly depends on the $\mathrm{pH}$ of the reaction solution; it can vary from 0.48 to $1.24 \mathrm{~V}$ when the $\mathrm{pH}$ is changed from neutral to alkaline [21]. As the time passes, polyborates are formed from $\mathrm{B}(\mathrm{OH})_{4}{ }^{-}$[50-52].

Sodium citrate is also a well-established reductant for the syntheses of noble-metal nanostructures due to its abundance and versatility to serve as both the reductant and stabilizer $[12,21,39]$. It can be found in four different forms as a function of $\mathrm{pH}$ and by increasing the $\mathrm{pH}$ value, an increased electron density available for donation during a redox process is achieved which leads to a stronger reducing capability [53]. Mechanistically, there are two reductants involved: (i) sodium citrate itself and (ii) acetone generated during the redox reaction [21].

According to our best knowledge, the direct comparison of the impact of Au seeds, differing by their surface species stemming solely from syntheses (i.e., poly/borates, borates, hydroxyborates and citrate-residues), on the final morphology of Au-Ag core-shell NSs has never been addressed so far. Therefore, it is the first aim of this study.

As the second main goal of this work, our attention is devoted to the order of reactants in the second step of seed-mediated growth of the final Au-AgNSs. Usually, the second step of $\mathrm{Au}-\mathrm{AgNSs}$ generation includes the preparation of a mixture of $\mathrm{AgNO}_{3}$ and $\mathrm{Au}$ seeds (whatever type), followed by the addition of Asc solution, i.e., Asc is added at the end of the seed-mediated growth procedure (e.g., [11,15,20,23,24,28,32,33]). Inspired by the work of Polte et al. [54,55], where the principles of metal NPs growth were discussed based on the concept of colloidal stability, we investigated the influence of the reverse order of reactants (i.e., Asc prior to $\mathrm{AgNO}_{3}$ ).

Finally, selected Au-AgNSs were employed in SERS detection of the model porphyrin TMPyP in its free base form. Thus, here described and investigated synthetic procedure of Ag shell generated on Au seeds, represents a new possibility of synthetic approaches to reach unperturbed (non-metalated) porphyrin SERS spectra. 


\section{Materials and Methods}

\subsection{Chemicals}

Silver nitrate $\left(\mathrm{AgNO}_{3}, 99.999 \%\right.$ purity, abbreviated as " $\mathrm{Ag}+$ " in sample code), sodium borohydride $\left(\mathrm{NaBH}_{4},>98 \%\right.$ purity), tetrachloroauric acid ( $\mathrm{HAuCl}_{4},>99 \%$ purity), L-ascorbic acid ( $\geq 99.0 \%$ purity, abbreviated as "Asc" in sample code), 5,10,15,20-tetrakis(1-methyl4-pyridyl)21H,23H-porphine molecules (TMPyP, 97\% dye content) were purchased from Sigma-Aldrich (St. Louis, MO, USA) and used as received (without any further purification).

All stock solutions were prepared with deionized water (purification system Milli-Q, Millipore Corp., Bedford, MA, USA). All glassware was cleaned with aqua regia acid (the mixture of nitric acid and hydrochloric acid in the ratio of 1:3) and copious amounts of deionized water prior to its usage.

\subsection{Nomenclature}

For easier comprehension and better orientation, a naming convention was developed for our seed solutions and final colloidal NP systems. Seed solutions are either freshly prepared (denoted by using "fr" in their code) or aged for 7 months (without any additional code)_Table 1. Different types of AuNPs serving as seeds are used: either borohydridereduced (AuBhr), or citrate-reduced (AuCitr). In the case of freshly prepared AuNP seeds using $\mathrm{NaBH}_{4}$ as a strong reducing agent, we distinguish between slightly hydrolyzed (labelled as "BH"), and hydrolyzed ("BOH") borohydride (i.e., aged for $2 \mathrm{~h}$ in an ice bath). The order of reactants in the second step of our seeded growth method is also reflected in the sample code as can be read in Table 1 .

Table 1. Nomenclature of AuNP seed solutions and final colloidal Au-AgNSs.

\begin{tabular}{cc}
\hline Seed Solution Code & Final Colloidal Au-AgNSs Code \\
\hline AuBH-fr & AuBH-fr_Ag+_Asc \\
AuBOH-fr & AuBOH-fr_Ag+_Asc \\
AuCitr-fr & AuCitr-fr_Ag+_Asc \\
AuBhr & AuBhr_Ag+_Asc \\
AuBhr & AuBhr_Asc_Ag+ \\
AuCitr & AuCitr_Ag+_Asc \\
AuCitr & AuCitr_Asc_Ag+ \\
\hline
\end{tabular}

\subsection{Syntheses of the AuNP Serving as Seeds}

(a) synthesis of AuBH-fr

The seed solution is synthesized by mixing $5 \mathrm{~mL}$ of freshly prepared $\mathrm{NaBH}_{4}$ solution (4.48 mM, submerged in an ice bath) with $5 \mathrm{~mL}$ of $0.94 \mathrm{mM} \mathrm{HAuCl}_{4}$ aqueous solution, and $10 \mathrm{~mL}$ of deionized water. The solution was then stirred at the rate of $1150 \mathrm{rpm}$ for 5 min. Subsequently, $0.5 \mathrm{~mL}$ of this AuNP seed solution was used for the synthesis of AuBH-fr_Ag+_Asc.

(b) synthesis of AuBOH-fr

The seed solution is synthesized by the same procedure as in (a), however, approx. 2-h-aged $\mathrm{NaBH}_{4}$ solution (4.48 mM, submerged all the time in an ice bath) was used. Subsequently, $0.5 \mathrm{~mL}$ of this AuNP seed solution was used for the synthesis of AuBOHfr_Ag+_Asc.

(c) synthesis of AuBhr (borohydride-reduced AuNPs aged for 7 months)

AuBhr seed solution was prepared according to the procedure published in [56] with small modifications-instead of reduction of $\mathrm{Ag}(\mathrm{I})$ salt, reduction of $\mathrm{Au}(\mathrm{III})$ salt is performed. Briefly, $3.43 \mathrm{mg} \mathrm{NaBH} 4$ was dissolved in $75 \mathrm{~mL}$ of deionized water submerged in an ice bath. The mixture was stirred at the rate of $1000 \mathrm{rpm}$ while adding drop-wise $9 \mathrm{~mL}$ of $2.2 \mathrm{mM} \mathrm{HAuCl}_{4}$ in the middle of the stirring vortex. The mixture was withdrawn from an ice bath after $6 \mathrm{~min}$ and subsequently stirred for $1 \mathrm{~h}$ until reaching room temperature. 
The AuBhr colloid was then stored in dark at room temperature for 7 months (such long time of ageing was induced by the limited access into the lab due to the COVID-pandemic) and used for the preparation of AuBhr_Ag+_Asc and AuBhr_Asc_Ag+ systems.

(d) synthesis of AuCitr-fr and AuCitr (citrate-reduced AuNPs freshly prepared and aged for 7 months, respectively)

It is a slightly modified Lee-Meisel method [57]. Briefly, AuCitr seed solution was obtained by bringing $200 \mathrm{~mL}$ of $0.2 \%$ sodium citrate solution to its boiling point in $500-\mathrm{mL}$ Erlenmeyer flask and adding $\mathrm{HAuCl}_{4}$ aqueous solution prepared by mixing $20.52 \mathrm{mg}$ of $\mathrm{HAuCl}_{4}$ in $10.26 \mathrm{~mL}$ of deionized water. The mixture was kept at boiling point by IKA CMAG HS7 magnetic stirrer with ceramic heating plate for $1 \mathrm{~h}$. Afterwards, the mixture was stirred for additional one hour until reaching room temperature. Freshly prepared AuCitr particles were used as seeds for AuCitr-fr_Ag+_Asc synthesis. The AuCitr colloid stored in dark at room temperature for 7 months (as mentioned above, due to COVID-pandemic) was then employed for the preparation of AuCitr_Ag+_Asc and AuCitr_Asc_Ag+ systems.

\subsection{Syntheses of the Final Colloidal Au-AgNSs}

Concentrations and volumes of $\mathrm{AgNO}_{3}$ and Asc were kept constant, as well as the same volume of Au seeds exploited in all preparations of Au-AgNSs as follows:

(i) AuBH-fr_Ag+_Asc: $0.5 \mathrm{~mL}$ of AuBH-fr was added to $12.5 \mathrm{~mL}$ of $0.2 \mathrm{mM} \mathrm{AgNO}$ aqueous solution, followed by $250 \mu \mathrm{L}$ of $10 \mathrm{mM}$ ascorbic acid aqueous solution. The final colloidal Au-AgNSs were stirred at the rate of $1350 \mathrm{rpm}$ for $10 \mathrm{~s}$, then at the rate of $850 \mathrm{rpm}$ for additional $25 \mathrm{~min}$.

(ii) AuBOH-fr_Ag+_Asc: the same synthetic procedure as (i), however, $0.5 \mathrm{~mL}$ of AuBOHfr was employed. The stirring and timing were the same as in (i).

(iii) AuBhr_Ag+_Asc: the same synthetic procedure as (i), however, $0.5 \mathrm{~mL}$ of AuBhr colloid was added. The stirring and timing were the same as in (i).

(iv) AuCitr-fr_Ag+_Asc: the synthetic procedure was the same as in (i), however, $0.5 \mathrm{~mL}$ of AuCitr-fr was introduced. The stirring and timing were the same as in (i).

(v) AuCitr_Ag+_Asc: the synthetic procedure was the same as in (i), however, $0.5 \mathrm{~mL}$ of AuCitr (i.e., aged AuCitr seeds) was employed. The stirring and timing were the same as in (i).

(vi) AuBhr_Asc_Ag+: the procedure of this Au-AgNSs preparation was very similar to that described in (iii) with the only exception: a reversed order of reactants was used during the second step. Briefly, $0.5 \mathrm{~mL}$ of the seed solution AuBhr (aged for 7 months) was added to $250 \mu \mathrm{L}$ of $10 \mathrm{mM}$ ascorbic acid aqueous solution, followed by the addition of $12.5 \mathrm{~mL}$ of $0.2 \mathrm{mM} \mathrm{AgNO}_{3}$ aqueous solution. The stirring and timing were the same as in (i).

(vii) AuCitr_Asc_Ag+: the synthetic procedure was the same as in (vi), however, $0.5 \mathrm{~mL}$ of AuCitr (instead of AuBhr) was employed.

Based on the assumptions that generated $\mathrm{Au}$ seeds are spherical with the mean diameter of approx. $20 \mathrm{~nm}$ (and/or $50 \mathrm{~nm}$ ) and all $\mathrm{Au}$ (III) was consumed into Au seeds, the minimal concentration of $\mathrm{Ag}(\mathrm{I})$ which covers the whole surface of Au seeds (monolayer $\mathrm{Ag}(\mathrm{I})$ coverage, i.e., Ag atoms placed next to each other on Au surfaces) can be calculated (details in Supporting Information). Taking into account the concentrations and volumes of $\mathrm{Au}$ (III) used in our experiments (AuBhr and AuCitr serving as seeds), the amount of the monolayer $\mathrm{Ag}(\mathrm{I})$ coverage is around $9.2 \times 10^{-9}$ mol for $20 \mathrm{~nm}$-size Au seed particles (while $3.7 \times 10^{-9} \mathrm{~mol} \mathrm{Ag}(\mathrm{I})$ for $50 \mathrm{~nm}$-size Au seed particles-Supporting Information). Hence, in both cases (AuBhr, AuCitr), the employed Ag(I) amount exceeds the monolayer $\mathrm{Ag}(\mathrm{I})$ value by more than two orders of magnitude.

All syntheses were prepared in triplicates by two different experimentalists to exclude any discrepancy and verify the reproducibility. 


\subsection{Methods}

UV-Vis spectra of freshly prepared and aged AuNP seeds, as well as final colloidal Au-AgNSs were recorded on spectrometer Specord PLUS 250 (ChromSpec, Analytic Jena, Jena, Germany), in the range between 190-1100 nm. Quartz cuvettes with $2.5 \mathrm{~mL}$ of a particular colloidal sample were used for the measurements. Deionized water in another quartz cuvette served as a reference.

Extinction spectra for kinetics measurements were recorded on the same UV-Vis spectrometer in the range between 190-900 nm. Quartz cuvette was filled with $750 \mu \mathrm{L}$ of the sample taken from the reaction mixture in a particular time interval elapsed from the addition of the last reactant of seed-mediated growth of Au-AgNSs (i.e., after Asc or $\mathrm{AgNO}_{3}$ ).

Transmission electron microscopic (TEM) imaging were performed by using Jeol 2010F transmission electron microscope (Jeol USA, Inc., Peabody, MA, USA), equipped with a LaB6 cathode (accelerating voltage $80 \mathrm{kV}-200 \mathrm{kV}$; CCD camera KEENview G2 (ResAlta Research Technologies, Golden, CO, USA). A 3- $\mu$ L drop of a particular colloidal sample was deposited onto a carbon-coated copper grid. Grids were allowed to dry at room temperature in a Petri dish covered by its lid for at least one day before performing TEM measurements.

Energy dispersive spectra (EDS) of selected samples were recorded on Oxford x-MAX 80T (SSD) (Oxford Instruments, Oxford, UK).

Dynamic light scattering (DLS) was employed to determine the size distribution of AuNP seeds and of final colloidal Au-AgNSs directly in solution. Zetasizer Nano Series (Malvern Instruments Ltd., Malvern, UK) using the laser beam of $633 \mathrm{~nm}$ wavelength, operating in the scattering angle of $173^{\circ}$ was employed. The measurement was performed at $25{ }^{\circ} \mathrm{C}$ in a disposable polystyrene cuvette filled with $1 \mathrm{~mL}$ of a particular colloidal sample, which was diluted with deionized water at 1:10 $v / v$ ratio. The measurement was set as "multiple narrow mode" resolution and automated number of "runs" during the measurement. A mean result of three measurements was recorded. Particle size distribution according to intensity is considered in our results and discussion section because it is the directly measured size distribution. Besides particle size distribution according to intensity, the software of Zetasizer Nano Series (Malvern Instruments Ltd, Malvern, UK) enables estimation of the size distribution according to number and/or volume. However, both latter size distributions are calculated with some assumptions which are not always valid in our systems and, thus, cannot be accepted. Therefore, we show and discuss only the size distribution based on intensity changes.

The same Zetasizer Nano Series (Malvern Instruments Ltd, Malvern, UK) was used for measuring zeta-potential of colloidal AuNP seeds and Au-AgNSs. The $0.75 \mathrm{~mL}$ of a particular sample (no dilution) was placed into a disposable zeta-potential cell and a mean result of three measurements was recorded.

$\mathrm{pH}$ values of the AuNP seeds and final colloidal Au-AgNSs were measured by using a standard laboratory $\mathrm{pH}$ meter inoLab (type 7110, Xylem Analytics, GmbH \& Co, Mainz, Germany).

Surface-enhanced Raman scattering (SERS) spectra were recorded on ProRaman-L spectrometer (TSI, Shoreview, MN, USA) equipped with diode laser of $785 \mathrm{~nm}$ wavelength (adjustable optical power output from zero to $300 \mathrm{~mW}$, electronic laser shutter control); high throughput fiber optics probe (O.D. $>8$ at laser wavelength); high sensitivity, ultra-low noise CCD spectrograph for $785 \mathrm{~nm}$ excitation (thermoelectrically cooled CCD detector to $\left.-60{ }^{\circ} \mathrm{C}\right)$; and RamanReader ${ }^{\circledR}$-L7B1 instrument control and data collection software. The SERS spectra of Au seeds and/or Au-AgNSs without and with TMPyP $\left(1 \times 10^{-8} \mathrm{M}\right.$ in the final SERS systems, as well as $1 \times 10^{-6} \mathrm{M}$ in the case of Au seeds) were measured in 1-cm quartz cuvettes (3/Q(10, ChromSpec, spol. s.r.o., Brno, Czech Republic) by using $300 \mathrm{~mW}$ laser power, integration time of $2 \mathrm{~s}$ and 60 acquisitions. The SERS spectra were recorded in the spectral range from 100 to $3300 \mathrm{~cm}^{-1}$, average spectral resolution of approx. $7 \mathrm{~cm}^{-1}$ 
(pixel resolution of approx. $1.8 \mathrm{~cm}^{-1}$ per pixel). Any smoothing and/or corrections of the recorded SERS spectra were omitted, automatic baseline correction was performed.

\section{Results and Discussion}

\subsection{Direct Impact of Au Seed Type on Morphologies of Final Au-AgNSs}

The effect of Au seed types on the morphologies of the final Au-AgNSs was investigated using TEM imaging. The characteristic TEM images of all Au seeds used in the present study are shown in Figure S1 in Supporting information. Since no polymers and/or large organic molecules (serving as capping agents) are used in our syntheses of Au-AgNSs, no organic layer around the final metallic NSs is detected using TEM. The contrast in TEM images of Au-AgNSs thus mirrors the presence of AuNPs, darker, and AgNPs, lighter. EDS (energy dispersive spectroscopy) was also performed in selected cases of the final AuAgNSs in order to give evidence about the simultaneous Au and Ag presence (Figure S2 in Supporting Information).

\subsubsection{Au-AgNSs Stemming from Au Seeds Prepared by Reduction Induced} by Borohydride

In order to demonstrate the influence of borohydride hydrolysis (and related changes in surface chemistry) during the formation of Au seeds, we investigated the effect of the degree of $\mathrm{NaBH}_{4}$ hydrolysis on the final $\mathrm{Au}-\mathrm{AgNSs}$ morphology. Indeed, freshly prepared (denoted as $\mathrm{BH}$ ) and/or two-hours aged borohydride (however, stored in an ice-bath so that the hydrolysis is slowed down and reduction strength is retained; denoted as $\mathrm{BOH}$ ) were used for AuNPs generation. AuNPs were, immediately after their preparation (when a characteristic red color of solution appeared), exploited as seeds (therefore denoted as " $\mathrm{fr}^{\text {") }}$ in the next step of Au-AgNSs formation. For the sake of a direct comparison, aged AuBhr serving as seeds (denoted simply as AuBhr) were also used for Au-AgNSs generation.

TEM imaging of the final Au-AgNSs prepared by using Au seeds generated via fresh vs. few-hours-aged borohydride (AuBH-fr_Ag+_Asc and AuBOH-fr_Ag+_Asc, respectively) revealed completely different morphologies (Figure $1 \mathrm{~A}-\mathrm{D}$, respectively) in comparison to those observed for aged Au seeds, i.e., AuBhr_Ag+_Asc (Figure 1E,F). AuBH-fr_Ag+_Asc manifested itself by Au cores surrounded by AgNPs (of much smaller sizes than Au seeds) which are directly attached to the surface of Au cores (Figure 1A,B). This resembles flower-like particles with many nanometer-sized interstices and SERS enhancement can be envisaged. In the case of AuBOH-fr_Ag+_Asc, a mixture of Au and Ag NPs relatively randomly dispersed was visualized (Figure 1C,D). In TEM images of AuBhr_Ag+_Asc (Figure 1E,F), each AuNP is surrounded by many small NPs which are supposed to be AgNPs. This assumption is made on the basis of a direct comparison with TEM images of particular Au seeds (Figure S2C in Supporting Information).

Interestingly, $\mathrm{Au}$ seeds generated by borohydride of different stage of hydrolysis are of different sizes and shapes: bigger and more asymmetrical in AuBH-fr than in $\mathrm{AuBOH}-\mathrm{fr}$ (compare Figure 1A-D, as well as Figure S1A,B in Supporting Information) although the time elapsed for their generation was the same. It confirmed the differences in reduction strength of freshly prepared vs. few-hours-aged borohydride; the latter being of a weaker reduction strength. Consequently, varying surface reactions are taking place on noble metal surfaces in the early stages of their formation. Similarly, this was demonstrated in the case of AgNPs in [48].

Furthermore, taking into account TEM results in Figure 1, it is thus a simple experimental proof that the degree of borohydride hydrolysis in the course of Au seeds generation has a strong impact not only on the size and shape of Au seeds, but also on the final Au-AgNSs morphology. 
A

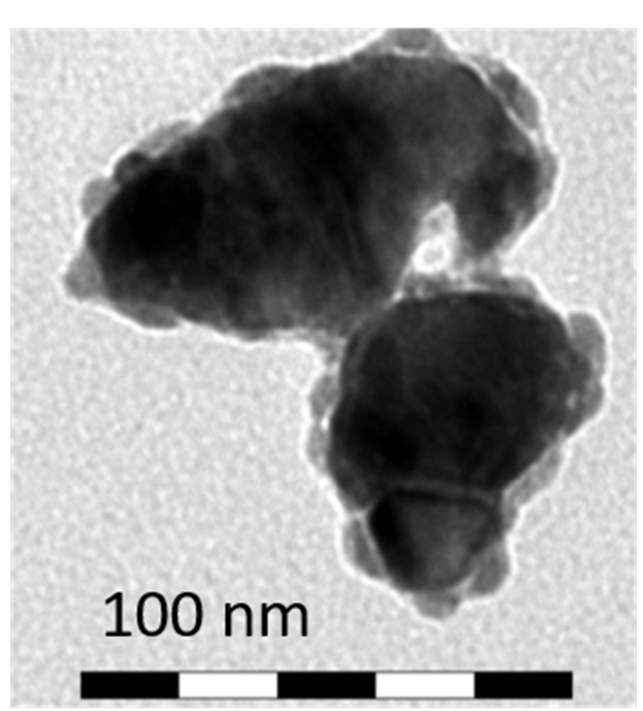

C

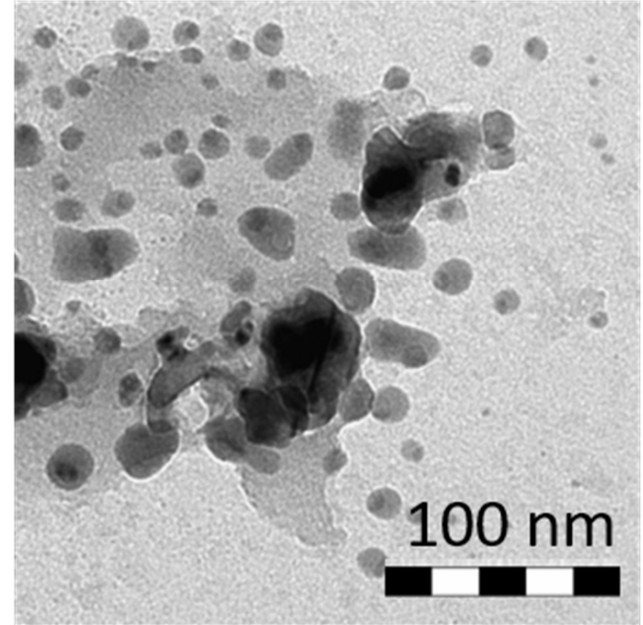

E

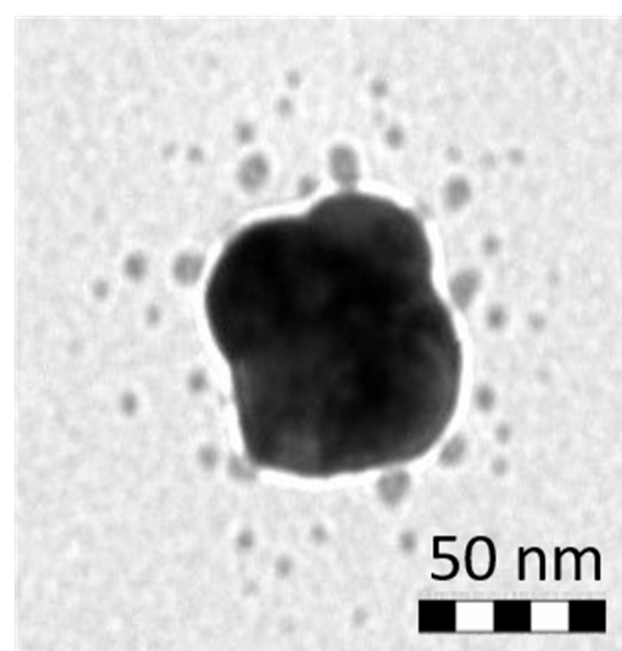

B

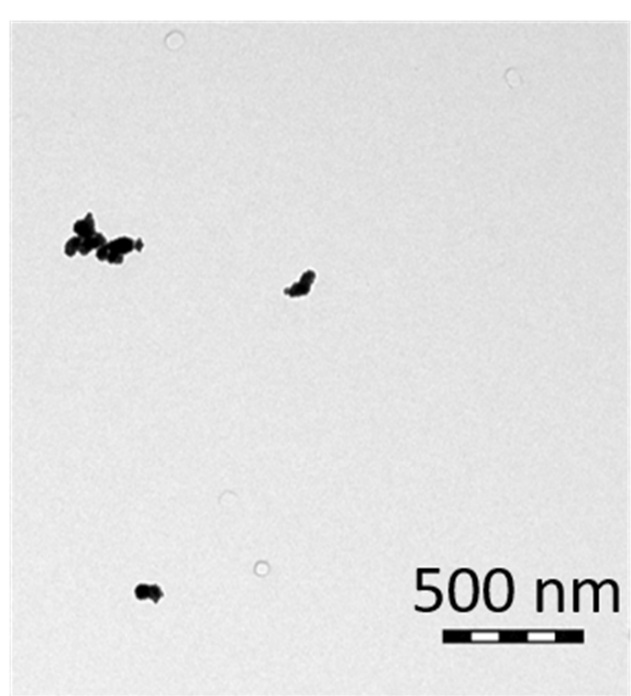

D

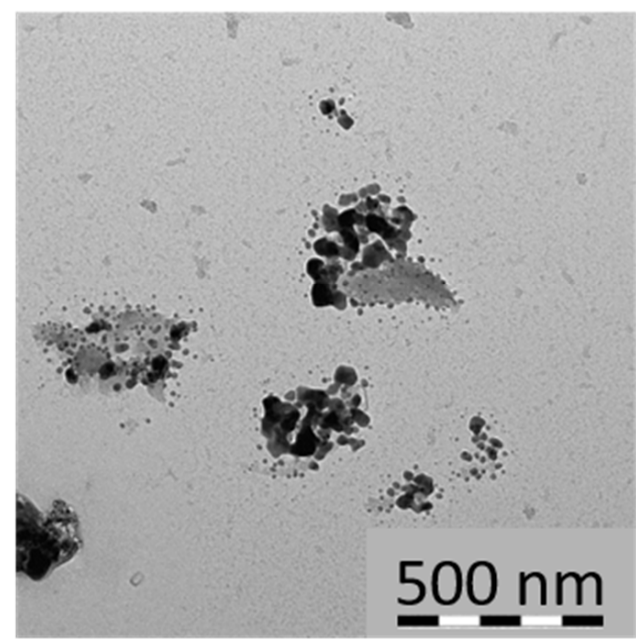

F

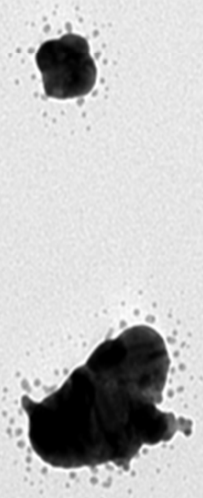

Figure 1. Representative TEM images of Au-AgNSs generated from borohydride-reduced Au seeds: (A,B) AuBHfr_Ag+_Asc, (C,D) AuBOH-fr_Ag+_Asc, (E,F) AuBhr_Ag+_Asc. 


\subsubsection{Au-AgNSs Stemming from Au Seeds Prepared by Reduction Induced by Citrate}

By changing the type of a reduction agent in Au seeds formation from borohydride to citrate, distinctly different morphologies were obtained. While AuNPs enveloped by a bunch of tiny AgNPs in the case of borohydride-reduced Au seeds were observed (Figure 1); a compact Ag layer around AuNPs was detected in the case of Au-AgNSs when citratereduced Au seeds were employed, i.e., either AuCitr-fr, or AuCitr (Figure 2). The latter arrangement is much more pronounced in the literature regardless of the (i) conditions of Au seed preparation: the same synthesis as in our case (e.g., [58]), whereas photochemically prepared Au seeds [59]; (ii) shape of Au seeds (e.g., [10]).
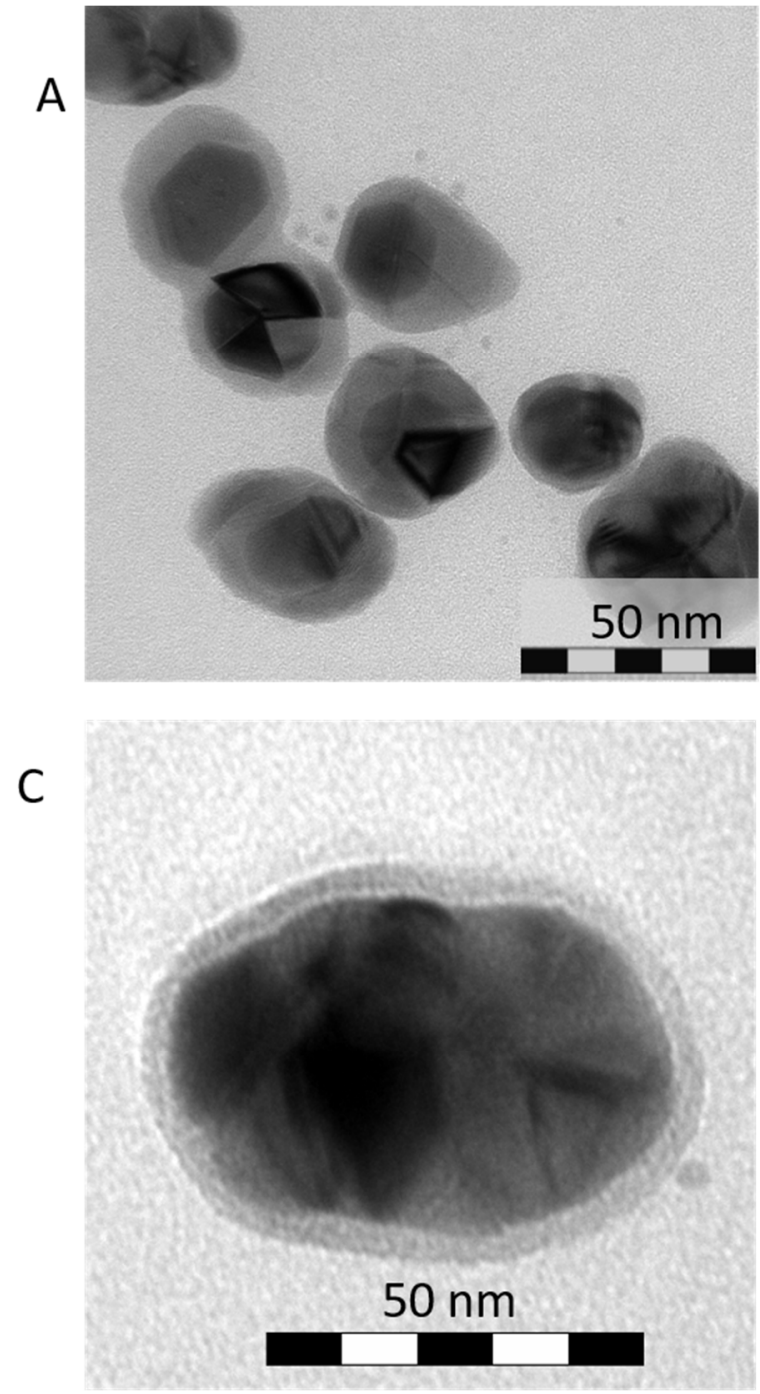

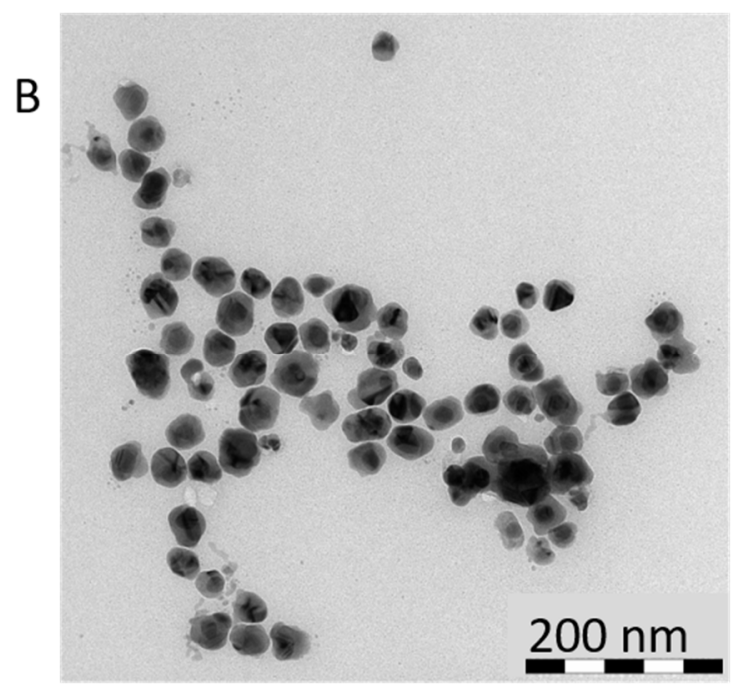

D

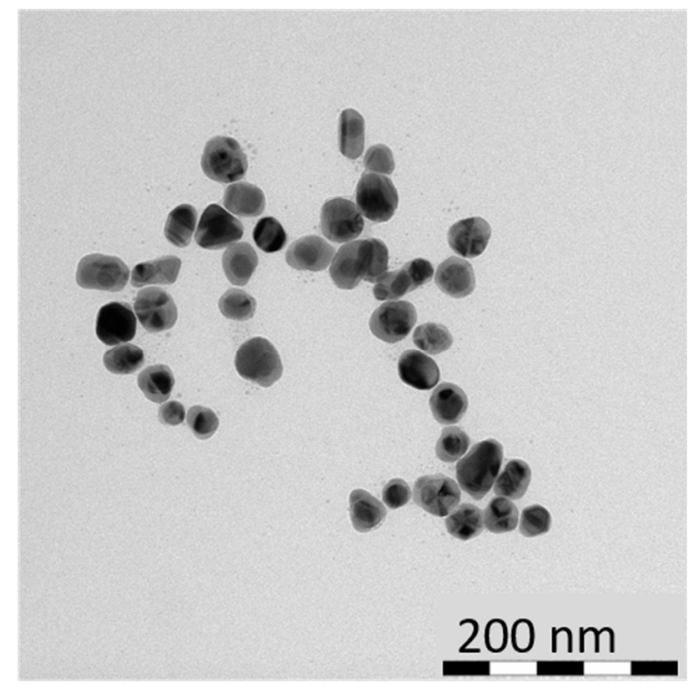

Figure 2. Representative TEM images of Au-AgNSs generated from citrate-reduced Au seeds: (A,B) AuCitr-fr_Ag+_Asc, (C,D) AuCitr__Ag+_Asc.

\subsubsection{Reason for Different Morphologies of Au-AgNSs}

It can be summed up that three different types of morphologies, schematically depicted in Scheme 1, were obtained simply by changing Au seeds. While type I represents a mixture of Au and Ag NPs, type II resembles flower-like particles with nanometer-sized interstices, and type III is characterized by a consistent layer of $\mathrm{Ag}$ around $\mathrm{Au}$ (Scheme 1). The reason for morphological differences of the final Au-AgNSs in the present study lies most probably in a completely different surface chemistry and species which are present at each type of Au surface. In AuBhr seeds, borates and polyborates (in aged systems) can be encountered, 
whereas residues of citrates and acetone in AuCitr seeds can be found. Citrates are known as chelating agents of silver cations [21,39]. Obviously, residues of citrates and/or acetone enable creation of a compact Ag layer around almost each Au seed when seeded-growth procedure of Au-AgNSs is performed. Therefore, it can be deduced that the creation of type III is caused by the chelating effect of citrate ions on silver cations.

1.

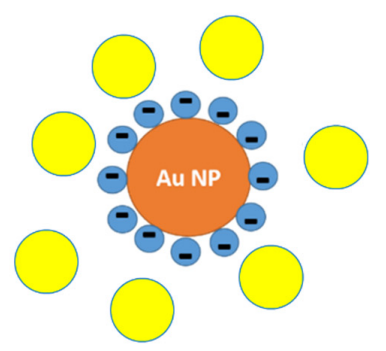

II.

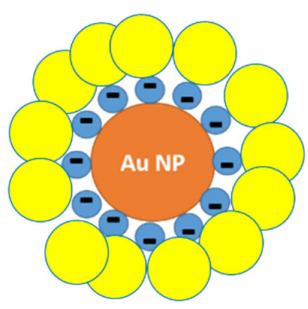

III.

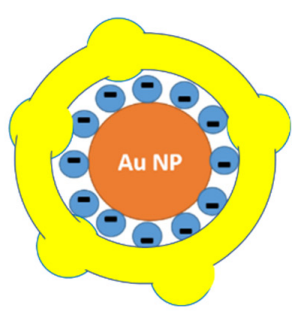

Scheme 1. Schematic depiction of three types of morphologies of final Au-AgNSs. Au seeds with negative envelope of ions (blue circles representing either (poly)borates and/or citrate residues) are surrounded by added Ag+. The Ag+, reduced by Asc in the second step of Au-AgNSs generation, is then surrounding the Au core and three different types of morphologies are generated based on surface chemistry of Au seeds: (I.) mixture of Au and Ag NPs, (II.) closely connected Ag NPs to the surface of Au seed in an uneven layer (flower-like morphology), (III.) forming a consistent layer of Ag around the Au seed.

Morphologies of type II (Scheme 1), observed when AuBH-fr seeds employed (Figure 1A,B), can be caused by the presence of still reactive borohydride on Au seeds. Indeed, it leads to the direct reduction of Ag+ in the very close vicinity of freshly prepared Au seeds.

On the contrary, morphologies of type I (Scheme 1), which are characteristic for AuBhr_Ag_Asc and AuBOH-fr_Ag_Asc (Figure 1C-F), are most probably induced by the presence of either polyborates, or borates which hinder the direct deposition of Ag+ on $\mathrm{Au}$ seed surfaces (i.e., poly/borates are not chelating agents of silver cations).

\subsection{Other Characteristics of Au-AgNSs Prepared by Using AuBhr or AuCitr Seeds \\ 3.2.1. Sizes of Au-AgNSs Determined by DLS and Values Discussed in Comparison to TEM}

DLS measurements of the final Au-AgNSs were performed in their "native" environment, i.e., in aqueous solutions, to confirm sizes and aggregation state of NSs which were visualized by TEM imaging. It is generally accepted that during TEM samples preparation, the samples are exposed to a drying process which can greatly influence the morphological patterns, especially in the case of aggregate formation. The DLS results for a few hours aged Au-AgNSs and aged Au seeds are listed in Table 2.

Table 2. Particle size distributions and $\mathrm{pH}$ values of selected few hours-aged Au-AgNSs and aged Au seeds.

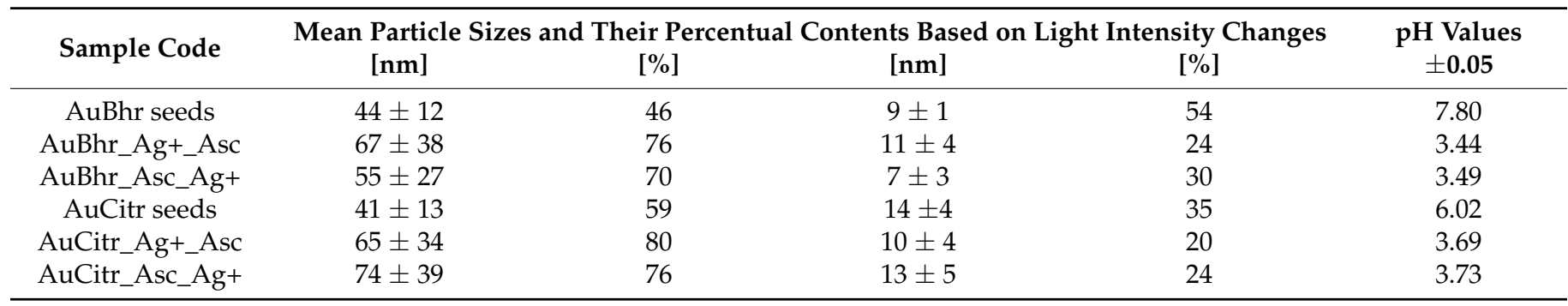

Obviously, there is a bimodal particle size distribution of the final Au-AgNSs as well as of original Au seeds based on DLS intensity (Table 2). AuBhr and AuCitr revealed two 
types of similar mean particle sizes (around 40 and $10 \mathrm{~nm}$ ), however, each of them in a different percentual content (Table 2).

In AuBhr_Ag+_Asc and AuCitr_Ag+_Asc, the majority of particle sizes (76\% and $80 \%$, respectively) seems to be concentrated around 67 and $65 \mathrm{~nm}$, respectively. The standard deviation is of a rather high value, $38 \mathrm{~nm}$ for AuBhr_Ag+_Asc and $34 \mathrm{~nm}$ for AuCitr_Ag+_Asc. It indicates that the systems still develop in the moment of DLS measurements. The second maximum of particle size distributions, contributing by a quarter in AuBhr_Ag+_Asc and by 20\% in AuCitr_Ag+_Asc, is centered at 11 and $10 \mathrm{~nm}$, respectively. It should be reminded that scattering intensity of bigger particles is higher than that of smaller particles [60]. Therefore, the portion of smaller particles is underestimated and that of bigger particles is overestimated in these results.

Furthermore, hydrodynamic diameter is assessed in DLS measurements while solely metallic parts of NSs are visualized in TEM images. Indeed, the final Au-AgNSs travel across the solution together with several shells of small organic molecules and ions stemming from their syntheses (residues of citrates and/or acetone, (poly)borates together with dehydroascorbate and other potential ascorbic acid residues). Hence, it may lead to differences between particle sizes determined by DLS vs. TEM.

Considering the structures showed in Figures $1 \mathrm{E}$ and $2 \mathrm{C}$, the overall hydrodynamic diameter can be expected around $70 \mathrm{~nm}$ which correlates well with the values in Table 2. Furthermore, either the generated AgNPs are responsible for the second most abundant diameter (around 11 and/or $10 \mathrm{~nm}$ ) detected by DLS, or Au seeds uncovered by Ag (less probable situation); their metallic parts (visualized by TEM in Figure 1and Figure 2) are well below these values. Based on DLS measurements, it becomes clear that an isolated small AgNP observed in the close vicinity of a gold seed with silver layer in representative TEM image of AuCitr_Ag+_Asc (Figure 2C), can stem from the drying process during TEM sample preparation. Similarly, many other small AgNPs in AuBhr_Ag+_Asc (Figure 1E) could be spread separately in the solution, moving thus independently of Au seeds as determined by DLS.

\subsubsection{Extinction Spectra of Au Seeds and of Final Au-AgNSs}

According to UV-Vis spectroscopy, the LSPR maximum of AuBhr is located at $515 \mathrm{~nm}$ (curve a in Figure 3A). Upon Au-AgNSs formation, this maximum is shifted to $397 \mathrm{~nm}$, LSPR is broadened with a shoulder around $350 \mathrm{~nm}$ and a significant red-tail (curve $b$ in Figure 3A). This red-tail is most probably induced (i) by the absence of Ag layer around AuNPs (as evidenced in Figure 1), hence, Au NPs still partially contribute to the extinction spectrum, as well as, (ii) by the formation of AgNPs aggregates. The intensity of the LSPR maximum of AuBhr_Ag+_Asc is rather low (curve b in Figure 3A). This can be explained by the fact that smaller AgNPs, which manifest themselves by a broader LSPR and possess much lower scattering cross-section [60], are present in AuBhr_Ag+_Asc as it was evidenced by TEM and DLS. 

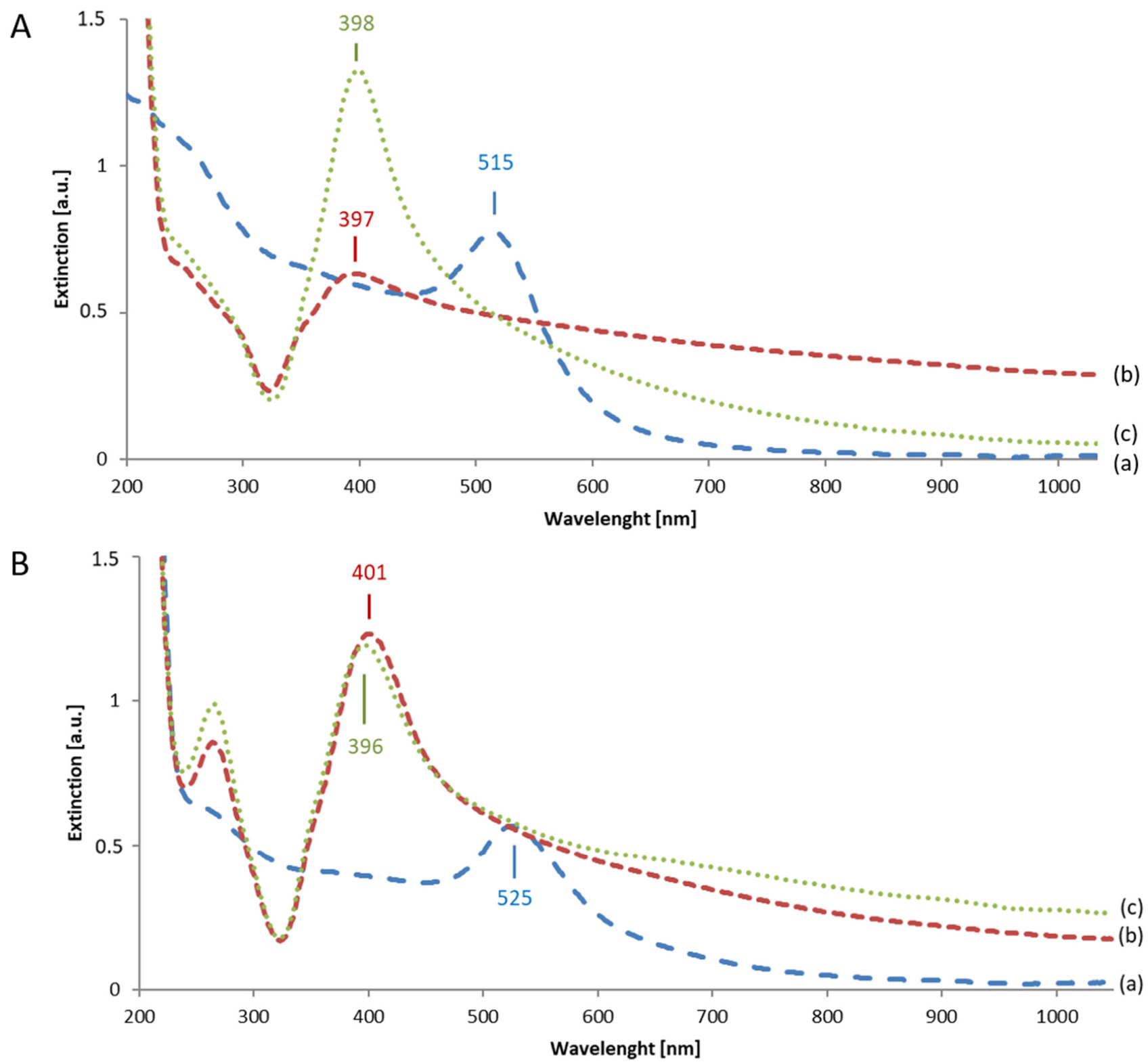

Figure 3. Characteristic UV-Vis spectra of two different Au seeds (curves (a)) and final Au-AgNSs stemming from these seeds when the classical (curves (b)) vs. reverse order of reactants (curves (c)) were employed. Briefly, in (A): curve (a) is AuBhr, curve (b) is AuBhr_Ag+_Asc, curve (c) is AuBhr_Asc_Ag+. In (B): curve (a) is AuCitr, (b) AuCitr_Ag+_Asc, (c) AuCitr_Asc_Ag+.

The LSPR maximum of AuCitr is positioned at $525 \mathrm{~nm}$ (curve a in Figure 3B). Obviously, bigger starting AuNPs in AuCitr than in the case of AuBhr are present which is consistent with TEM imaging (Figure S1 in Supporting Information). The LSPR maximum of AuCitr_Ag+_Asc shifted to $401 \mathrm{~nm}$ and a slight red-tail can be distinguished (curve b in Figure 3B). Similarly, as in AuBhr_Ag+_Asc (curve b in Figure 3A), a shoulder at shorter wavelengths is detected in UV-Vis spectrum of AuCitr_Ag+_Asc (curve b in Figure 3B). We assume that it belongs to the transversal mode of LSPR [61] of asymmetric Au-AgNSs (as for instance visualized in Figure 2C). Simultaneously, the red-tail in UV-Vis spectra of AuCitr_Ag+_Asc can be attributed to a fraction of NPs being of such asymmetric shape and possessing longitudinal mode of LSPR [61]. Last, but not least, the band around $265 \mathrm{~nm}$ detected in AuCitr_Ag+_Asc can be attributed to ascorbate and/or dehydroascorbate. 
Considering the results and discussed correlations and dependencies, distinctly different morphologies of the final Au-AgNSs and their related spectroscopic properties were achieved simply by using two different Au seed types (i.e., without any other additional surfactant).

\subsection{Classical vs. Reverse Order of Reactants in Seed-Mediated Growth Procedure of Au-AgNSs}

As mentioned in the introduction, only a few researchers have dealt with the effect of the order of reactants in the seed-mediated growth of Au-AgNSs so far. Moreover, their seeds were surface modified by surfactants which were intentionally added into the reaction mixture. Here, we selected aged forms of Au seeds (i.e., without any further surfactants added) and performed the synthetic procedures of the seed-mediated growth with the reverse order of reactants. In other words, Asc was mixed with Au seeds and, subsequently, $\mathrm{AgNO}_{3}$ was introduced. This can influence the characteristics of electrostatic double layer around AuNPs as depicted in Scheme 2A,B.

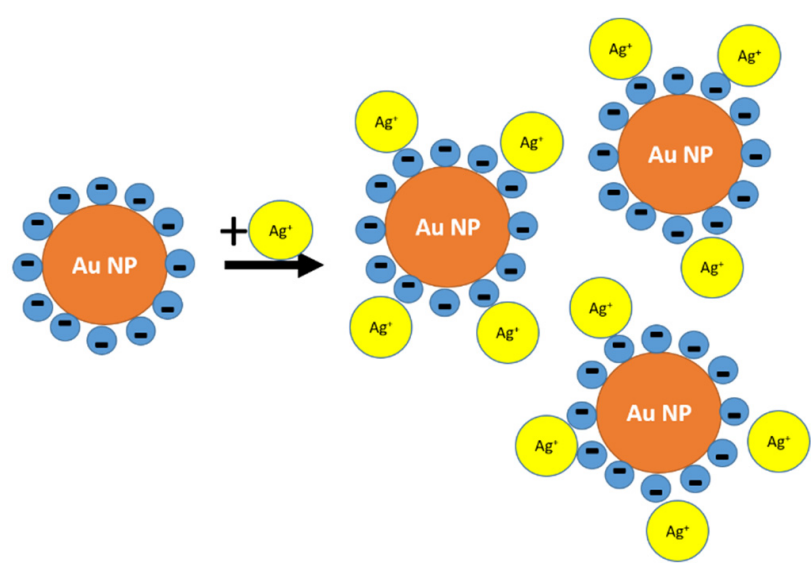

(A)

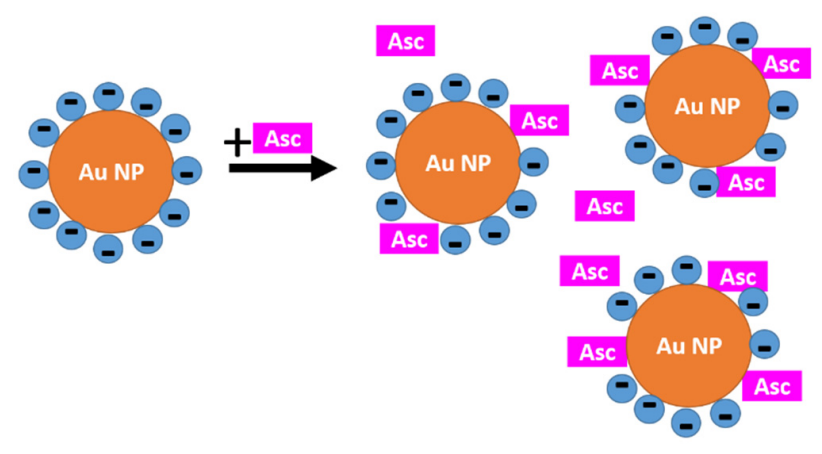

(B)

Scheme 2. Schematic depiction of Au seeds with negative envelope of ions (blue circles representing either (poly)borates, or citrate residues) when the classical (A), or reverse (B) order of reactants in the second step of seed-mediated growth used. Only the addition of the first reactant is depicted in each step, i.e., Ag+ in Scheme (A), whereas Asc in Scheme (B).

While added $\mathrm{Ag}(\mathrm{I})$ can partially compensate the negatively charged envelope of $\mathrm{Au}$ seeds (Scheme 2A), leading thus to a localization of silver ions in the close vicinity of AuNPs; the addition of Asc prior to Ag(I) (Scheme 2B), can result in molecular exchange of negatively charged ions surrounding AuNPs, i.e., Asc directly adsorbs on Au seed surfaces. Consequently, an anisotropic growth (similarly as in [62]) can be more pronounced in the latter case.

As it was proofed by TEM imaging for AuBhr_Asc_Ag+ and AuCitr_Asc_Ag+ (Figure 4): irregularly shaped particles resulted from synthesis with the reverse order of reactants (Asc prior to $\mathrm{AgNO}_{3}$ ). Since we are not playing with the final concentration of $\mathrm{AgNO}_{3}$, neither with the presence and concentration of any additional ions (such as for instance halides as in refs $[32,63,64])$, the only parameter responsible for such changes in the final Au-AgNSs morphology must be the order of reactants. Therefore, the envisaged anisotropic growth due to the adsorption of Asc on Au seed surfaces was confirmed. 
A

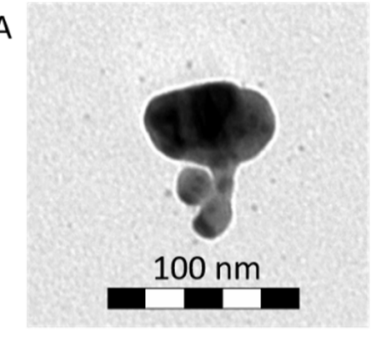

C

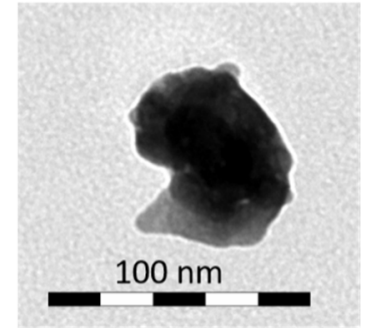

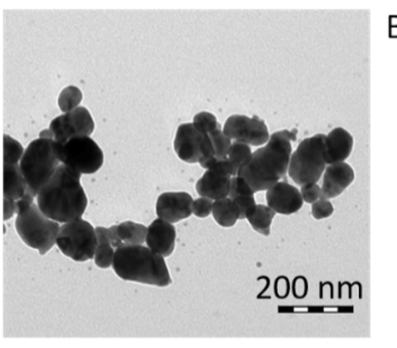

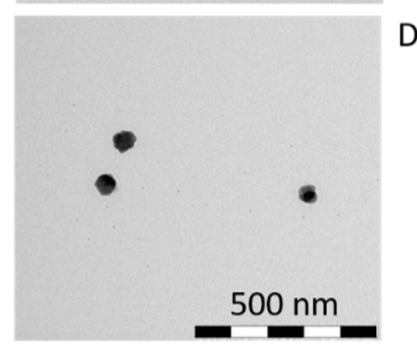

Figure 4. Representative TEM images of $\mathrm{Au}-\mathrm{AgNSs}$ prepared by using reverse order of reactants, i.e., Asc prior to Ag+: (A,B) AuBhr_Asc_Ag+, (C,D) AuCitr_Asc_Ag+.

UV-Vis spectra of AuBhr_Asc_Ag+ and AuCitr_Asc_Ag+ were recorded and are directly compared with those of AuBhr_Ag+_Asc and AuCitr_Ag+_Asc in Figure 3A,B, respectively. The LSPR maximum of AuBhr_Asc_Ag+ (curve c in Figure 3A) is located around $398 \mathrm{~nm}$ and manifests itself by an increased intensity in comparison to that of AuBhr_Ag+_Asc (curve b in Figure 3A). The red-tail in AuBhr_Asc_Ag+ (curve c in Figure 3A) is observed, however, it is less pronounced than that of AuBhr_Ag+_Asc (discussed in the previous section).

The LSPR maximum of AuCitr_Asc_Ag+ (curve c in Figure 3B) is of a similar intensity as that of AuCitr_Ag+_Asc (curve b in Figure 3B). The position of LSPR maximum of AuCitr_Asc_Ag+ (curve c in Figure 3B) can be found around $396 \mathrm{~nm}$ which is 5-nm blueshifted in comparison to AuCitr_Ag+_Asc (curve b in Figure 3B). Obviously, the red-tail and shoulder around $350 \mathrm{~nm}$ are detected in both systems, i.e., in AuCitr_Ag+_Asc (curve b in Figure 3B), as well as in AuCitr_Asc_Ag+ (curve c in Figure 3B), revealing thus the presence of asymmetric and prolongated NSs - in accordance with TEM images in Figure 4. Moreover, the band of ascorbate residues and/or dehydroascorbate (positioned at around $265 \mathrm{~nm}$ ) evidenced their presence in the close vicinity of AuNPs even after several hours elapsed from the beginning of the synthesis. This confirms the idea of the direct adsorption of ascorbate and/or its residues on Au seed surfaces during the second step of seed-mediated growth.

Results of DLS measurements of AuBhr_Asc_Ag+ and AuCitr_Asc_Ag+ are summarized in Table 2 for the sake of a direct comparison with the systems discussed in previous section. Obviously, bimodal particle size distribution repeats in both systems similarly as it was in cases of AuBhr_Ag+_Asc and AuCitr_Ag+_Asc. However, while the mean size diameter of bigger particles of $55 \pm 27 \mathrm{~nm}$ prevails (particle size distribution based on intensity) in AuBhr_Asc_Ag+; it is of $74 \pm 39 \mathrm{~nm}$ in AuCitr_Asc_Ag+. The mean size diameter of the fraction of smaller particles is centered at $7 \pm 3 \mathrm{~nm}$ and $13 \pm 5 \mathrm{~nm}$ for AuBhr_Asc_Ag+ and AuCitr_Asc_Ag+, respectively (Table 2).

The differences in mean particle sizes of NSs generated by classical (Ag+ prior to Asc) vs. reverse (Asc prior to Ag+) order of reactants give evidence about the importance of this factor during the seed-mediated growth procedure. Moreover, it can be stated that the type of AuNPs has an even bigger impact on particle size distribution when reverse order of reactants is used. In other words, while bigger mean size particles are generated in AuBhr_Ag+_Asc than in AuBhr_Asc_Ag+; the trend is opposite in systems using AuCitr as seeds. Hence, the order of reactants influences the particle size distribution of the final Au-AgNSs. Indirectly, it confirmed the idea about Asc adsorption on AuNP surfaces 
and particularly, the role of (poly)borates vs. residues of citrates and/or acetone on $\mathrm{Au}$ seed surfaces: while the addition of Asc prior to $\mathrm{Ag}^{+}$stabilizes AuBhr (by electro-steric stabilization); the same procedure destabilizes AuCitr (most probably due to a competitive adsorption of residues of citrates/acetone and Asc on AuNP surfaces).

Importantly, the $\mathrm{pH}$ values were determined for Au seeds (7.80 in AuBhr, whereas 6.02 in AuCitr), as well as, for the final Au-AgNSs (listed in Table 2). In both Au seeds solutions, Asc is in the dissociated form (because the pKa value is 4.2 ref. [65]), i.e., as ascorbate. While the final Au-AgNSs containing AuBhr seeds reached the $\mathrm{pH}$ values of 3.44 and 3.49; the systems containing AuCitr seeds revealed the $\mathrm{pH}$ values of 3.69 and 3.73. There is no wonder that the values were the same for each pair of Au-AgNSs within the experimental error (0.05) (Table 2) because the concentrations of all reactants are the same in classical and reverse order of reactants during the seed-mediated growth. Simultaneously, it was found by $\mathrm{pH}$ measurements that non-dissociated form of Asc should be present (if unconsumed) in the final Au-AgNSs.

\subsection{Kinetics of $A u-A g N S s$ Generation}

UV-Vis spectroscopy is an ideal tool to investigate the process of Au-AgNSs generation due to the fact that Au seeds as well as the final Au-AgNSs possess surface plasmons. In Figure 5, extinction spectra in particular time intervals elapsed from the addition of the last reactant in the process of seed-mediated growth of Au-AgNSs are shown. The spectra are shifted from each other by a constant value in y-axis for the sake of their better mutual comparison. Due to the usage of stacked arrangement in Figure 5, the shape and changes in intensity of the extinction spectra can be immediately distinguished even by a naked eye.
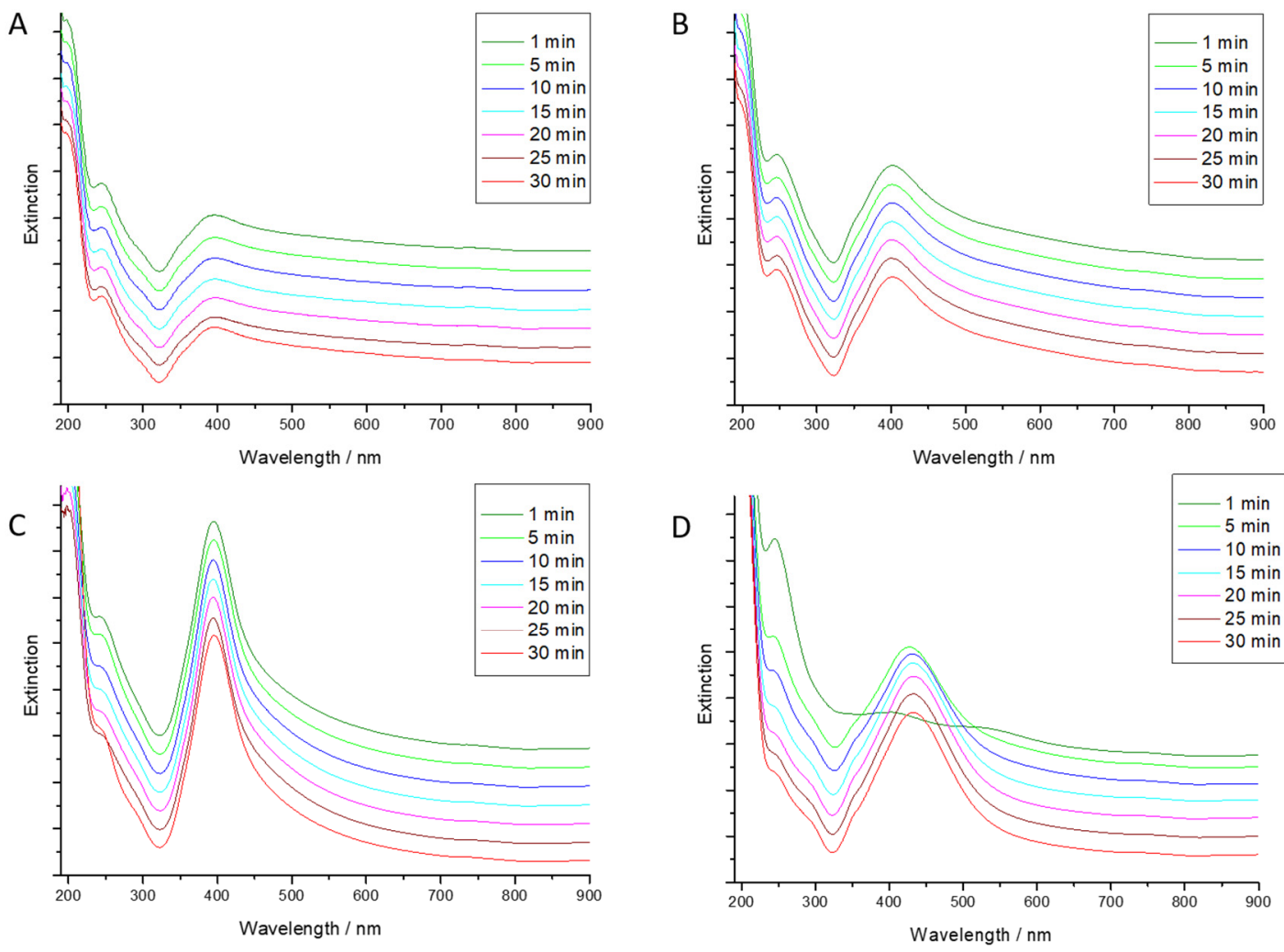

Figure 5. Stacked extinction spectra of the course of the generation of Au-AgNSs: (A) AuBhr_Ag+_Asc, (B) AuCitr_Ag+_Asc, (C) AuBhr_Asc_Ag+, (D) AuCitr_Asc_Ag+. Time in legends represents the interval elapsed from the addition of the last reactant (i.e., Asc in classical vs. $\mathrm{AgNO}_{3}$ in reverse order of reactants).

Evidently, the process of reduction of Ag+ on Au seeds is taking place within the first minute and no further changes in surface plasmon extinctions are observed when the classical 
order of reactants is used (Figure 5A,B) and/or in the case of AuBhr_Asc_Ag+ (Figure 5C) because LSPR of Ag dominates the spectra. On the contrary, the process is slowed down in the reverse order of reactants (Asc prior to $\mathrm{Ag}+$ ) when using AuCitr seeds (Figure 5D).

It can be concluded that the process of citrate residues replacement by Asc at AuCitr surface is much slower than the replacement of (poly)borates by Asc at AuBhr surface. Moreover, this corroborates the idea of a sort of destabilization of AuCitr seeds where residues of citrates and/or aceton are slowly replaced by Asc.

Long-term stability of Au-AgNSs was also investigated and discussed, but due to lack of space it is discussed in Supporting Information.

\subsection{SERS Application of Au-AgNSs}

We assume that ascorbates, dehydroascorbates, (poly)borates, and oxidation products of citrates, which are available on surfaces of Au-AgNSs, can influence the detection of tetracationic TMPyP, especially the type of its SERS-spectral form. Four Au-AgNSs were investigated concerning their SERS-activity by using TMPyP: AuBhr_Ag+_Asc, AuBhr_Asc_Ag+, AuCitr_Ag+_Asc, AuCitr_Asc_Ag+.

Prior to the addition of TMPyP solution, the aggregation states of the four Au-AgNSs were first checked by recording their UV-Vis spectra. Then, after the addition of TMPyP, the UV-Vis spectra were remeasured to determine the spectral changes induced by the process of TMPyP and NSs interaction (see in Figure S3 in Supporting Information). Consequently, a degree of $\mathrm{Au}-\mathrm{AgNSs}$ aggregation can be estimated and the extent of resonance of a particular system with the used laser wavelength can be evaluated. Generally, the more in resonance (laser wavelength with the band of adsorbate-NSs ensemble), the better SERS signal of the adsorbate should be obtained.

Considering our excitation laser wavelength $(785 \mathrm{~nm})$ and the extinction spectra of $\mathrm{Au}$ AgNSs with TMPyP (Figure S3 in Supporting Information), more intensive SERS-spectral pattern of TMPyP can be envisaged in cases of Au-AgNSs prepared by using AuCitr seeds than in the Au-AgNSs exploiting AuBhr seeds. This correlates well with the assumption based on zeta potential values of these Au-AgNSs (in Table S1 in Supporting Information): $\mathrm{Au}-\mathrm{AgNSs}$ with AuCitr seeds are more prone to aggregation, which was also evidenced by UV-Vis spectra (Figure S3 in Supporting Information), than Au-AgNSs with AuBhr seeds.

In Figure 6, characteristic SERS spectra of each Au-AgNSs alone (black curves) and together with TMPyP (colored curves) are shown. Obviously, all four Au-AgNSs manifested themselves by relatively simple spectral features with the two well-developed most intensive bands: around $250 \mathrm{~cm}^{-1}$ and $1642 \mathrm{~cm}^{-1}$. While the former can be attributed to Ag-OOC- [66] of dehydroascorbate and/or ascorbate residues because it is found in all four Au-AgNSs (Figure 6A-D); the latter stems from deformation vibrations of water molecules. Other bands of weak intensity positioned at around 490,600,1050, and $1420 \mathrm{~cm}^{-1}$ can be found in SERS-spectra of Au-AgNSs (black curves in Figure 3A-D). Based on peak positions, they could be assigned to dehydroascorbate and/or ascorbate residues present at the surface of Au-AgNSs.

The addition of TMPyP to Au-AgNSs results in changes of SERS-spectral pattern: the peak at $250 \mathrm{~cm}^{-1}$ enormously increased in intensity and many characteristic peaks of TMPyP appeared (in Figure 6A-D). Particularly, the SERS pattern of free-base TMPyP (as clearly determined in [40]) can be unambiguously distinguished by: (i) doublet positioned at around 336 and $406 \mathrm{~cm}^{-1}$, (ii) peak located at approx. $1006 \mathrm{~cm}^{-1}$, (iii) doublet at 1336 and $1366 \mathrm{~cm}^{-1}$. The only missing characteristic peak of free-base TMPyP SERS-spectral form is that positioned at $1562 \mathrm{~cm}^{-1}$ which is most probably shifted to 1548 and/or $1554 \mathrm{~cm}^{-1}$ in our cases (blue and red curves in Figure 6A-D, respectively). 

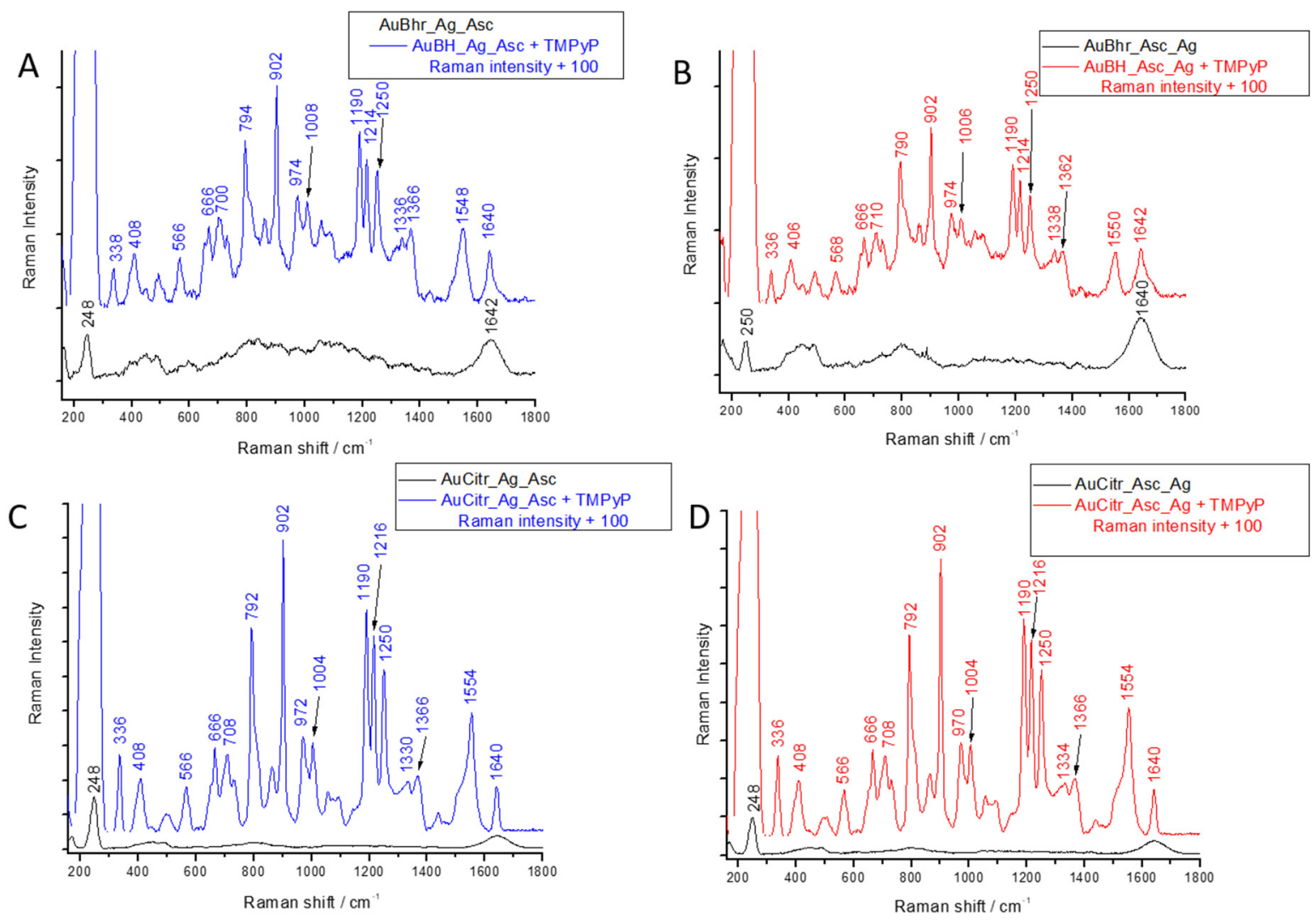

Figure 6. Detailed SERS signal of TMPyP (colored curves) interacting with (A) AuBhr_Ag+_Asc, (B) AuBhr_Asc_Ag+, (C) AuCitr_Ag+_Asc, (D) AuCitr_Asc_Ag+. Black curves show the SERS signal of each Au-AgNSs system without TMPyP addition. Increment of Raman intensity is 100 in all four figures. SERS spectra were recorded using 785nm excitation laser wavelength $(300 \mathrm{~mW})$ and 60 acquisitions for 2 s integration time.

The final TMPyP concentration was intentionally chosen to reach the value of $1 \times 10^{-8} \mathrm{M}$ because it is well below the calculated monolayer coverage of TMPyP on Au-AgNSs (more than one order of magnitude, for detailed calculation see Supporting Information). Therefore, all molecules of TMPyP should be able to interact directly with Au-AgNSs.

We assume that free-base TMPyP is detected due to the presence of ascorbic acid residues (manifesting themselves by the intensive peak at $250 \mathrm{~cm}^{-1}$ ) which serve as a type of molecular spacer-similarly as mercaptoacids in [37] and gluconic or glucuronic acids in [38]. It can be thus concluded that free-base form of TMPyP in submicromolar concentrations $(10 \mathrm{nM})$ is detected in all four Au-AgNSs regardless the type of Au seeds, as well as order of reactants in the second step of the seed-mediated growth procedure (compare SERS spectral patterns in blue and red curves in Figure 6A-D, respectively). This can be of interest in bio-analytical detection of porphyrins.

Based on negative zeta potential values of $\mathrm{Au}-\mathrm{AgNSs}$ (listed in Supporting Information in Table S1), aggregation caused by TMPyP addition (verified by UV-Vis spectra -Figure S3 in Supporting Information), and SERS detection of free-base TMPyP (Figure 6A-D), we propose an ionic interaction between tetracationic TMPyP and negatively charged dehydroascorbates and ascorbic acid residues present at Au-AgNSs surface. For the sake of a direct comparison, TMPyP was added into AgBhr colloid (separately prepared and aged for 9 months - experimental details are in Supporting Information) where characteristic SERS spectral peaks of metalation markers of Ag(I)-TMPyP were detected (398, $1342,1546 \mathrm{~cm}^{-1}$ ) — see Figure S4 in Supporting Information. Moreover, TMPyP SERSspectral pattern was checked using Au seeds prepared by borohydride and/or citrate reduction in order to compare with SERS features of TMPyP on Au-Ag NSs (in Figure S5 in Supporting Information). Obviously, the metalation markers of Ag-TMPyP cannot be 
detected since no Ag is present in Au seeds. Importantly, the SERS signal of TMPyP on $\mathrm{Au}-\mathrm{AgNSs}$ is better than that obtained by using Au seeds alone.

As for the intensity of TMPyP SERS-signal (Figure 6A-D), it correlates well with the trend proposed by interpretation of their UV-Vis spectra (Figure S3 in Supporting Information): more intensive in Au-AgNSs containing AuCitr as seeds than in Au-AgNSs exploiting AuBhr seeds. There are slight intensity changes of TMPyP signal (based on the intensity of the peak located, for instance, at $1190 \mathrm{~cm}^{-1}$ ) in Au-AgNSs containing AuCitr seeds when the order of reactants changed: TMPyP signal is a little bit more intensive in AuCitr_Ag+_Asc than in AuCitr_Asc_Ag+ (Figure 6C,D). Similarly, SERS signal of TMPyP is more pronounced in AuBhr_Ag+_Asc than in AuBhr_Asc_Ag+ (Figure 6A,B). It can be explained by different surface chemistry and characters of electric double layer surrounding Au-AgNSs which was induced by the order of reactants in the second step of the seed-mediated growth as it was schematically depicted in Scheme 2 and discussed in previous sections.

The enormous increase of the SERS intensity of the peak attributed to dehydroascorbate and/or ascorbate residues (located at $250 \mathrm{~cm}^{-1}$ ) induced by TMPyP addition to $\mathrm{Au}-\mathrm{AgNSs}$, can be explained by the aggregation process caused by the addition of tetracationic molecules of TMPyP to negatively charged $\mathrm{Au}-\mathrm{AgNSs}$ (i.e., revealing negative zeta potential values as discussed in section of Supporting Information when long-term stability discussed). Consequently, the LSPR peak is red-shifted and comes more in resonance with the excitation laser wavelength, leading thus to the observed SERS intensity increase. Interestingly, there are obvious differences in systems with classical vs. reverse order of reactants: the peak of $250 \mathrm{~cm}^{-1}$ is more enhanced in Au-AgNSs containing AuBhr as seeds when the order Asc prior to Ag+ (i.e., the reverse order of reactants) used; while its enhancement is higher in AuCitr_Ag+_Asc than in AuCitr_Asc_Ag+ (Figure S6 in Supporting Information). Taking into account the assumption depicted in Scheme 2, Asc can replace weakly adsorbed (poly)borates and citrates, however, the former possibly more easily than the latter (as evidenced by the kinetics of Au-AgNSs formation in the previous section), leading thus to the observed differences in SERS signal stemming from residues of Asc and dehydroascorbate.

Based on SERS spectra, it can be summed up that both factors, Au seed types and the order of reactants in the second step of the seed-mediated growth, play a role in quantitative, but not qualitative SERS-spectral behavior of the final Au-AgNSs when these are allowed to interact with a cationic adsorbate via ionic interaction. Importantly, the free base form of TMPyP is detected in all four selected Au-AgNSs types, therefore reporting a well-developed envelope of organic molecules around each Au-AgNSs which prevents the metalation to occur.

\section{Conclusions}

Core-shell Au-AgNSs were prepared by a seed-meditated growth exploiting several different types of $\mathrm{Au}$ seeds and varying the order of $\mathrm{AgNO}_{3}$ and Asc addition (classical: $\mathrm{Ag}+$ followed by Asc, and/or reverse order: Asc prior to $\mathrm{Ag}+$ ). It was revealed that the type of Au seeds, as well as the order of reactants in the second step of the seed-mediated growth procedure, both had a great impact on the final Au-AgNSs characteristics as determined by TEM imaging, UV-Vis spectroscopy, DLS, and zeta potential measurements. While AuNPs enveloped by a bunch of tiny AgNPs in the case of borohydride-reduced Au seeds were observed; a compact Ag layer around AuNPs was detected in the case of Au-AgNSs when citrate-reduced $\mathrm{Au}$ seeds were employed. Moreover, an envelope of organic molecules (dehydroascorbate and Asc residues) is detected on each Au-AgNSs as determined by spectroscopic measurements (SERS, UV-Vis) as well as based on negative zeta potential values. When the selected as-prepared Au-AgNSs applied in SERS detection of the model tetracationic porphyrin, 5,10,15,20-tetrakis(1-methyl-4-pyridyl)21H,23H-porphine (TMPyP), unperturbed (free-base) form of TMPyP was detected in submicromolar concentrations $(10 \mathrm{nM})$, thus bioanalytical application of these Au-AgNSs can be envisaged. 
Supplementary Materials: The following are available online at https: / www.mdpi.com/article/ 10.3390/nano11092185/s1, Figure S1: TEM images of Au seeds: (A) AuBH-fr, (B) AuBOH-fr, (C) AuBhr, (D) AuCitr-fr, (E) AuCitr, Figure S2: EDS (energy dispersive spectroscopic) analysis for selected TEM images of AuBhr_Ag+_Asc (A) and AuCitr_Ag+_Asc (B), Figure S3: Extinction spectra of each Au-AgNSs measured prior (black curves) and after TMPyP addition (colored curves) for (A) AuBhr_Ag+_Asc, (B) AuBhr_Asc_Ag+, (C) AuCitr_Ag+_Asc, (D) AuCitr_Asc_Ag+, and (E) absorption spectrum of TMPyP in $1 \times 10^{-6} \mathrm{M}$ concentration in the final systems, Figure S4: SERS spectrum of TMPyP $\left(1 \times 10^{-6} \mathrm{M}\right)$ adsorbed on AgNPs prepared by borohydride reduction (AgBhr) and aged for 9 months, Figure S5: Overlaid SERS spectra of TMPyP $\left(1 \times 10^{-6} \mathrm{M}\right.$ in orange and $1 \times 10^{-8} \mathrm{M}$ in magenta) adsorbed on Au seeds reduced by: (A) borohydride, (B) citrate. Spectra of Au seeds without TMPyP addition (black curves) are shown for the sake of direct comparison. SERS spectra were recorded by using $785 \mathrm{~nm}$ excitation laser line, $300 \mathrm{~mW}$, 2s 30x, and automatic baseline corrected, Figure S6: Whole intensity range of SERS spectra of TMPyP (final concentration of $1 \times 10^{-8} \mathrm{M}$ ) adsorbed on: (A) AuBhr_Ag+_Asc, (B) AuBhr_Asc_Ag+, (C) AuCitr_Ag+_Asc, (D) AuCitr_Asc_Ag+, Table S1: Particle size distributions and zeta potential values of selected 9 months-aged Au-AgNSs.

Author Contributions: Conceptualization, K.Š.; Formal analysis, I.V.; Funding acquisition, K.Š.; Investigation, I.V.; Methodology, K.Š.; Project administration, K.Š.; Resources, K.Š.; Supervision, K.Š.; Validation, I.V.; Writing—original draft, I.V.; Writing—review \& editing, K.Š. Both authors have read and agreed to the published version of the manuscript.

Funding: This research was funded by the Grant Agency of Czech Republic, grant number 19-03207S, and by Ministry of Education Youth and Sports, grant number 8J20FR024.

Data Availability Statement: The data is included in the main text and/or the supplementary materials.

Acknowledgments: Our special thanks are devoted to Lukáš Nosek and Jana Stráská for TEM imaging; the latter for EDS analysis as well. Kateřina Kumbárová is thanked for an independent repetition of experiments (in the framework of her Diploma Thesis). Helena Sedláčková is thanked for English corrections.

Conflicts of Interest: The authors declare no conflict of interest.

\section{References}

1. Bai, T.; Lu, P.; Zhang, K.; Zhou, P.; Liu, Y.; Guo, Z.; Lu, X. Gold/silver bimetallic nanocrystals: Controllable synthesis and biomedical applications. J. Biomed. Nanotechnol. 2017, 13, 1178-1209. [CrossRef]

2. Gilroy, K.D.; Ruditskiy, A.; Peng, H.C.; Qin, D.; Xia, Y. Bimetallic nanocrystals: Syntheses, properties, and applications. Chem. Rev. 2016, 116, 10414-10472. [CrossRef] [PubMed]

3. Hutter, E.; Fendler, J.H. Exploitation of localized surface plasmon resonance. Adv. Mater. 2004, 16, 1685-1706. [CrossRef]

4. Eustis, S.; El-Sayed, M.A. Why gold nanoparticles are more precious than pretty gold: Noble metal surface plasmon resonance and its enhancement of the radiative and nonradiative properties of nanocrystals of different shapes. Chem. Soc. Rev. 2006, 35, 209-217. [CrossRef] [PubMed]

5. Odom, T.W.; Nehl, C.L. How gold nanoparticles have stayed in the light: The 3M's principle. ACS Nano 2008, 2, 612-616. [CrossRef]

6. Schwartzberg, A.M.; Zhang, J.Z. Novel optical properties and emerging applications of metal nanostructures. J. Phys. Chem. C 2008, 112, 10323-10337. [CrossRef]

7. Liz-Marzán, L.M. Tailoring surface plasmons through the morphology and assembly of metal nanoparticles. Langmuir. 2006, 22, 32-41. [CrossRef] [PubMed]

8. Vinod, M.; Gopchandran, K.G. Bimetallic Au-Ag nanochains as SERS substrates. Curr. Appl. Phys. 2015, 15, 857-863. [CrossRef]

9. Kumari, M.M.; Jacob, J.; Philip, D. Green synthesis and applications of Au-Ag bimetallic nanoparticles. Spectrochim. Acta Part A Mol. Biomol. Spectrosc. 2015, 137, 185-192. [CrossRef]

10. Tsuji, M.; Matsuo, R.; Jiang, P.; Miyamae, N.; Ueyama, D.; Nishio, M.; Hikino, S.; Kumagae, H.; Kamarudin, K.S.N.; Tang, X.L. Shape-dependent evolution of Au@Ag core-shell nanocrystals by PVP-assisted N,N-dimethylformamide reduction. Cryst. Growth Des. 2008, 8, 2528-2536. [CrossRef]

11. Khlebtsov, B.N.; Liu, Z.; Ye, J.; Khlebtsov, N.G. Au@Ag core/shell cuboids and dumbbells: Optical properties and SERS response. J. Quant. Spectrosc. Radiat. Transf. 2015, 167, 64-75. [CrossRef]

12. Qi, Y.; Zhu, J.; Li, J.J.; Zhao, J.W. Multi-mode optical detection of iodide based on the etching of silver-coated gold nanobipyramids. Sensors Actuators B Chem. 2017, 253, 612-620. [CrossRef]

13. Song, L.; Mao, K.; Zhou, X.; Hu, J. A novel biosensor based on Au@Ag core-shell nanoparticles for SERS detection of arsenic (III). Talanta 2016, 146, 285-290. [CrossRef] [PubMed] 
14. Xin, J.; Zhang, F.; Gao, Y.; Feng, Y.; Chen, S.; Wu, A. A rapid colorimetric detection method of trace Cr (VI) based on the redox etching of Agcore-Aushell nanoparticles at room temperature. Talanta 2012, 101, 122-127. [CrossRef]

15. Yang, Y.; Shi, J.; Kawamura, G.; Nogami, M. Preparation of Au-Ag, Ag-Au core-shell bimetallic nanoparticles for surface-enhanced Raman scattering. Scr. Mater. 2008, 58, 862-865. [CrossRef]

16. Ghodselahi, T.; Arsalani, S.; Neishaboorynejad, T. Synthesis and biosensor application of Ag@Au bimetallic nanoparticles based on localized surface plasmon resonance. Appl. Surf. Sci. 2014, 301, 230-234. [CrossRef]

17. Tang, X.; Tsuji, M. Synthesis of Au core Au/Ag alloy shell nanoparticles using branched Au nanoparticles as seeds. Cryst. Eng. Comm. 2011, 13, 72-76. [CrossRef]

18. Mallin, M.P.; Murphy, C.J. Solution-Phase Synthesis of Sub-10 nm Au-Ag Alloy Nanoparticles. Nano Lett. 2002, 11, 1235-1237. [CrossRef]

19. Han, S.W.; Kim, Y.; Kim, K. Dodecanethiol-derivatized Au/Ag bimetallic nanoparticles: TEM, UV/VIS, XPS, and FTIR analysis. J. Colloid Interface Sci. 1998, 278, 272-278. [CrossRef]

20. Imura, Y.; Akiyama, R.; Furukawa, S.; Kan, R.; Morita-Imura, C.; Komatsu, T.; Kawai, T. Au-Ag Nanoflower Catalysts with Clean Surfaces for Alcohol Oxidation. Chem.-An Asian J. 2019, 14, 547-552. [CrossRef]

21. Rodrigues, T.S.; Zhao, M.; Yang, T.H.; Gilroy, K.D.; da Silva, A.G.M.; Camargo, P.H.C.; Xia, Y. Synthesis of Colloidal Metal Nanocrystals: A Comprehensive Review on the Reductants. Chem. Eur. J. 2018, 24, 16944-16963. [CrossRef] [PubMed]

22. Stamplecoskie, K.G.; Scaiano, J.C. Light emitting diode irradiation can control the morphology and optical properties of silver nanoparticles. J. Am. Chem. Soc. 2010, 132, 1825-1827. [CrossRef] [PubMed]

23. Wang, Y.; Zhang, P.; Mao, X.; Fu, W.; Liu, C. Seed-mediated growth of bimetallic nanoparticles as an effective strategy for sensitive detection of Vitamin C. Sensors Actuators B Chem. 2016, 231, 95-101. [CrossRef]

24. Ding, S.J.; Zhu, J. Tuning the surface enhanced Raman scattering activity of gold nanocubes by silver coating. Appl. Surf. Sci. 2015, 357, 487-492. [CrossRef]

25. Pei, L.; Ou, Y.; Yu, W.; Fan, Y.; Huang, Y.; Lai, K. Au-Ag Core-Shell Nanospheres for Surface-Enhanced Raman Scattering Detection of Sudan i and Sudan II in Chili Powder. J. Nanomater. 2015, 16, 215. [CrossRef]

26. Contreras-Caceres, R.; Dawson, C.; Formanek, P.; Fischer, D.; Simon, F.; Janke, A.; Uhlmann, P.; Stamm, M. Polymers as templates for au and Au@Ag bimetallic nanorods: Uv-vis and surface enhanced raman spectroscopy. Chem. Mater. 2013, 25, 158-169. [CrossRef]

27. Sau, T.K.; Murphy, C.J. Seeded high yield synthesis of short Au nanorods in aqueous solution. Langmuir 2004, 20, 6414-6420. [CrossRef]

28. Bakshi, M.S.; Possmayer, F.; Petersen, N.O. Role of different phospholipids in the synthesis of pearl-necklace-type gold-silver bimetallic nanoparticles as bioconjugate materials. J. Phys. Chem. C 2007, 111, 14113-14124. [CrossRef]

29. Dai, L.; Song, L.; Huang, Y.; Zhang, L.; Lu, X.; Zhang, J.; Chen, T. Bimetallic Au/Ag Core-Shell Superstructures with Tunable Surface Plasmon Resonance in the Near-Infrared Region and High Performance Surface-Enhanced Raman Scattering. Langmuir 2017, 33, 5378-5384. [CrossRef]

30. Zheng, P.; Hu, J.; Shen, G.; Jiang, J.; Yu, R.; Liu, G. Synthesis, structure and growth mechanism of size and shape tunable Au/Ag bimetallic nanoparticles. Chinese J. Chem. 2009, 27, 2137-2144. [CrossRef]

31. Yang, Z.; Chang, H.T. Anisotropic syntheses of boat-shaped core-shell Au-Ag nanocrystals and nanowires. Nanotechnology 2006, 17, 2304-2310. [CrossRef]

32. Lu, L.; Burkey, G.; Halaciuga, I.; Goia, D.V. Core-shell gold/silver nanoparticles: Synthesis and optical properties. J. Colloid Interface Sci. 2013, 392, 90-95. [CrossRef] [PubMed]

33. Imura, Y.; Mori, T.; Morita-Imura, C.; Kataoka, H.; Akiyama, R.; Kurata, H.; Kawai, T. Preparation and length control of waterdispersible ultrathin gold and silver bimetallic nanowires. Colloids Surfaces A Physicochem. Eng. Asp. 2018, 543, 9-14. [CrossRef]

34. Langer, J.; de Aberasturi, D.J.; Aizpurua, J.; Alvarez-Puebla, R.A.; Auguié, B.; Baumberg, J.J.; Bazan, G.C.; Bell, S.E.J.; Boisen, A.; Brolo, A.G.; et al. Present and future of surface-enhanced Raman scattering. ACS Nano 2020, 14, 28-117. [CrossRef] [PubMed]

35. Wang, R.; Yao, Y.; Shen, M.; Wang, X. Green synthesis of AuAtAg nanostructures through a seed-mediated method and their application in SERS. Colloids Surfaces A Physicochem. Eng. Asp. 2016, 492, 263-272. [CrossRef]

36. Cotton, T.M.; Schultz, S.G.; van Duyne, R.P. Surface-Enhanced Resonance Raman Scattering from Cytochrome c and Myoglobin Adsorbed on a Silver Electrode. J. Am. Chem. Soc. 1980, 102, 7960-7962. [CrossRef]

37. Šmejkal, P.; Vlčková, B.; Procházka, M.; Mojzeš, P.; Pfleger, J. SERRS spectra of cationic free-base porphyrin species adsorbed on laser ablated Ag colloids modified by mercaptoacetate spacers. J. Mol. Struct. 1999, 482-483, 225-229. [CrossRef]

38. Šišková, K.; Bečička, O.; Mašek, V.; Šafářová, K.; Zbořil, R. Spacer-free SERRS spectra of unperturbed porphyrin detected at 100 fM concentration in Ag hydrosols prepared by modified Tollens method. J. Raman Spectrosc. 2012, 43, 689-691. [CrossRef]

39. Siskova, K.; Vlckova, B.; Turpin, P.Y.; Thorel, A.; Grosjean, A. Porphyrins as SERRS spectral probes of chemically functionalized Ag nanoparticles. Vib. Spectrosc. 2008, 48, 44-52. [CrossRef]

40. Vlčková, B.; Šmejkal, P.; Michl, M.; Procházka, M.; Mojzeš, P.; Lednický, F.; Pfleger, J. Surface-enhanced resonance Raman spectroscopy of porphyrin and metalloporphyrin species in systems with Ag nanoparticles and their assemblies. J. Inorg. Biochem. 2000, 79, 295-300. [CrossRef]

41. Procházka, M.; Turpin, P.Y.; Štěpánek, J.; Vlčková, B. SERRS of free base porphyrin in laser-ablated colloids: Evidence for three different spectral porphyrin forms. J. Raman Spectrosc. 2002, 33, 758-760. [CrossRef] 
42. Šišková, K.; Vlćková, B.; Turpin, P.Y.; Thorel, A.; Procházka, M. Laser ablation of silver in aqueous solutions of organic species: Probing Ag nanoparticle-Adsorbate systems evolution by surface-enhanced raman and surface plasmon extinction spectra. $J$. Phys. Chem. C 2011, 115, 5404-5412. [CrossRef]

43. Šmejkal, P.; Šišková, K.; Vlčková, B.; Pfleger, J.; Šloufová, I.; Šlouf, M.; Mojzeš, P. Characterization and surface-enhanced Raman spectral probing of silver hydrosols prepared by two-wavelength laser ablation and fragmentation. Spectrochim. Acta Part A Mol. Biomol. Spectrosc. 2003, 59, 2321-2329. [CrossRef]

44. Jia, G.; Feng, Z.; Wei, C.; Li, C. Multifunctional human serum albumin in the surface-enhanced Ramanspectroscopy of porphyrin: Demetalation promoter, molecular spacer andstabilizer. J. Raman Spectrosc. 2010, 41, 1615-1620. [CrossRef]

45. Vlčková, B.; Matějka, P.; Šimonová, J.; Čermáková, K.; Pančoška, P.; Baumruk, V. Surface-enhanced resonance Raman spectra of free base 5,10,15,20-tetrakis(4-carboxyphenyl)porphyrin and its silver complex in systems with silver colloid: Direct adsorption in comparison to adsorption via molecular spacer. J. Phys. Chem. 1993, 97, 9719-9729. [CrossRef]

46. Song, C.; Abell, J.L.O.; He, Y.; Murph, S.H.; Cui, Y.; Zhao, Y. Gold-modified silver nanorod arrays: Growth dynamics and improved SERS properties. J. Mater. Chem. 2012, 22, 1150-1159. [CrossRef]

47. van Hyning, D.L.; Zukoski, C.F. Formation mechanisms and aggregation behavior of borohydride reduced silver particles. Langmuir 1998, 14, 7034-7046. [CrossRef]

48. Polte, J.; Tuaev, X.; Wuithschick, M.; Fischer, A.; Thuenemann, A.F.; Rademann, K.; Kraehnert, R.; Emmerling, F. Formation mechanism of colloidal silver nanoparticles: Analogies and differences to the growth of gold nanoparticles. ACS Nano 2012, 6, 5791-5802. [CrossRef] [PubMed]

49. Polte, J.; Erler, R.; Thünemann, A.F.; Sokolov, S.; Ahner, T.T.; Rademann, K.; Emmerling, F.; Kraehnert, R. Nucleation and growth of gold nanoparticles studied via in situ small angle X-ray scattering at millisecond time resolution. ACS Nano. 2010, 4, 1076-1082. [CrossRef]

50. Gardiner, J.A.; Collat, J.W. Kinetics of the Stepwise Hydrolysis of Tetrahydroborate Ion. J. Am. Chem. Soc. 1965, 87, 1692-1700. [CrossRef]

51. Gardiner, J.A.; Collat, J.W. The Hydrolysis of Sodium Tetrahydroborate. Identification of an Intermediate. J. Am. Chem. Soc. 1964, 86, 3165-3166. [CrossRef]

52. Andrieux, J.; Demirci, U.B.; Hannauer, J.; Gervais, C.; Goutaudier, C.; Miele, P. Spontaneous hydrolysis of sodium borohydride in harsh conditions. Int. J. Hydrogen Energy. 2011, 36, 224-233. [CrossRef]

53. Dong, X.; Ji, X.; Wu, H.; Zhao, L.; Li, J.; Yang, W. Shape control of silver nanoparticles by stepwise citrate reduction. J. Phys. Chem. C 2009, 113, 6573-6576. [CrossRef]

54. Polte, J. Fundamental growth principles of colloidal metal nanoparticles - a new perspective. Cryst. Eng. Comm. 2015, 17, 6809-6830. [CrossRef]

55. Wuithschick, M.; Witte, S.; Kettemann, F.; Rademann, K.; Polte, J. Illustrating the formation of metal nanoparticles with a growth concept based on colloidal stability. Phys. Chem. Chem. Phys. 2015, 17, 19895-19900. [CrossRef]

56. Šišková, K.M.; Machala, L.; Tuček, J.; Kašlík, J.; Mojzeš, P.; Zbořil, R. Mixtures of L-amino acids as reaction medium for formation of iron nanoparticles: The order of addition into a ferrous salt solution matters. Int. J. Mol. Sci. 2013, 14, 19452-19473. [CrossRef]

57. Lee, P.C.; Meisel, D. Adsorption and surface-enhanced Raman of dyes on silver and gold sols. J. Phys. Chem. 1982, 86, 3391-3395. [CrossRef]

58. Ko, F.H.; Tai, M.R.; Liu, F.K.; Chang, Y.C. Au-Ag core-shell nanoparticles with controllable shell thicknesses for the detection of adenosine by surface enhanced Raman scattering. Sensors Actuators B Chem. 2015, 211, 283-289. [CrossRef]

59. McGilvray, K.L.; Fasciani, C.; Bueno-Alejo, C.J.; Schwartz-Narbonne, R.; Scaiano, J.C. Photochemical strategies for the seedmediated growth of gold and gold-silver nanoparticles. Langmuir 2012, 28, 16148-16155. [CrossRef]

60. Lakowicz, J.R. Radiative decay engineering 5: Metal-enhanced fluorescence and plasmon emission. Anal. Biochem. 2005, 337, 171-194. [CrossRef] [PubMed]

61. Reguera, J.; Langer, J.; de Aberasturi, D.J.; Liz-Marzán, L.M. Anisotropic metal nanoparticles for surface enhanced Raman scattering. Chem. Soc. Rev. 2017, 46, 3866-3885. [CrossRef] [PubMed]

62. González-Rubio, G.; Scarabelli, L.; Guerrero-Martínez, A.; Liz-Marzán, L.M. Surfactant-Assisted Symmetry Breaking in Colloidal Gold Nanocrystal Growth. Chem. Nano. Mat. 2020, 6, 698-707. [CrossRef]

63. Lohse, S.E.; Burrows, N.D.; Scarabelli, L.; Liz-Marzán, L.M.; Murphy, C.J. Anisotropic noble metal nanocrystal growth: The role of halides. Chem. Mater. 2014, 26, 34-43. [CrossRef]

64. Langille, M.R.; Personick, M.L.; Zhang, J.; Mirkin, C.A. Defining rules for the shape evolution of gold nanoparticles. J. Am. Chem. Soc. 2012, 134, 14542-14554. [CrossRef] [PubMed]

65. Nermin, Y. Vitamin C-An Update on Current Uses and Functions; Chapter in Book; LeBlanc, J.G., Ed.; InTech Open: London, UK, 2018; ISBN 978-1-78923-896-9. [CrossRef]

66. Munro, C.H.; Smith, W.E.; Garner, M.; Clarkson, J.; White, P.C. Characterization of the surface of a citrate-reduced colloid optimized for use as a substrate for surface-enhanced resonance Raman scattering. Langmuir 1995, 11, 3715-3720. [CrossRef] 